\title{
The impact of Industry 4.0 on the relationship between TPM and
}

\section{maintenance performance}

\begin{abstract}
Purpose - In this paper we examine the impact of Industry 4.0 (I4.0) technologies on the relationship between Total Productive Maintenance (TPM) practices and maintenance performance.
\end{abstract}

Design/methodology/approach - Data collection was carried out through a multinational survey with 318 respondents from different manufacturing companies located in fifteen countries. Multivariate data techniques were applied to analyze the collected data. Diffusion of Innovations Theory (DIT) was the adopted theoretical lens for our research.

Findings - Our findings indicate that I4.0 technologies that aim at processing information to support decision-making and action-taking have a direct effect on maintenance performance. Technologies oriented to sensing and communicating data among machines, people, and products seem to moderate the relationship between TPM practices and maintenance performance. However, the extent of such moderation varies according to the practices involved, sometimes leading to negative effects.

Originality/value - With the advances of I4.0, there is an expectation that several maintenance practices and performance may be affected. Our study provides empirical evidence of these relationships, unveiling the role of I4.0 for maintenance performance improvement.

Keywords: Industry 4.0, Total productive maintenance, Performance, Empirical study.

\section{Introduction}


The Fourth Industrial Revolution also denoted as Industry 4.0 (I4.0), is characterized by an increased level of automation and interconnectivity enabled by the incorporation of disruptive technologies, such as big data and Internet-of-Things (IoT) (Lasi et al., 2014; Fettermann et al., 2018). I4.0 combines cyber and physical environments, resulting in more flexible and responsive organizations and promptly meeting customers' expectations (Dalenogare et al., 2018; Chirumalla, 2021). I4.0 technologies positively impact the way manufacturing shop floors are managed and organized and influence organizations' business models, products, and services (Tortorella et al., 2019; Urbinati et al., 2019). Several manufacturing sectors have applied I4.0 technologies and principles, such as automotive (Llopis-Albert et al., 2021), pharmaceutical (Reinhardt et al., 2020), and food (Kayikci et al., 2020).

Integrating I4.0 technologies into traditional maintenance promotes the evolution of existing maintenance practices and concepts, enabling more efficient information and physical flows (Silvestri et al., 2020). Total Productive Maintenance (TPM) stands out among the most common maintenance approaches, with increased adoption in the 1990s (Ahuja and Khamba, 2008a). TPM aims at maximizing equipment effectiveness throughout its entire life cycle, heavily relying on the engagement of all levels of the organization and the utilization of complementary practices (Nakajima, 1988). It fosters process stability by properly maintaining production equipment, leading to less frequent breakdowns and quality defects (Wickramasinghe and Perera, 2016). Moreover, TPM combines different components of traditional maintenance, which usually fall into four categories (Coleman et al., 2017): reactive maintenance, planned maintenance, proactive maintenance, and predictive maintenance. Those types of maintenance complement each other towards improved operational performance and present different opportunities when considering their digitalization (Nowakowski et al., 2018).

I4.0 arguably might boost maintenance practices through the use of integrated sensors and rapid data processing, enabling the development of innovative methods and enhancing equipment 
efficiency and reliability (Al-Najjar et al., 2018; Klathae and Ruangchoengchum, 2019). New enabling technologies, such as Internet-of-Things (IoT), cloud computing, big data, and augmented reality, have been pushing maintenance practices forward, overcoming traditional challenges and paving the way to novel approaches (IBM, 2017). Technology integration also tends to raise the expectations regarding maintenance performance since it might help improve maintenance times, support decision-making, and minimize human errors ( $R e$ and Bordegoni, 2014; Mourtzis et al., 2020; 2021). To underpin such an innovative process, companies may need to revise their maintenance policies and the roles of maintenance and production employees (Bokrantz et al., 2017; 2020). Despite the frenzy related to the potential benefits from I4.0 to maintenance performance (Mourtzis et al., 2020), empirical evidence is still scarce (Zonta et al., 2020). Additionally, there is a lack of studies investigating the integration between I4.0 technologies and TPM practices. Such gap motivated our study, giving rise to the following research question:

$R Q$. What is the role of I4.0 technologies on the relationship between TPM practices and maintenance performance?

This study examines the effect of I4.0 technologies on the relationship between TPM practices and maintenance performance through a multinational survey with 318 respondents from different manufacturing companies. Multivariate data techniques were applied to analyze the collected data. Given the purpose and nature of this research, we conceptually grounded it on the Diffusion of Innovations theory (DIT) (Rogers, 2003). DIT seeks to explain how, why, and at what rate new ideas and technology spread, arguing that diffusion is a process by which an 
innovation is communicated over time among the participants in a social system (Greenhalgh et al., 2004), such as a manufacturing organization.

The contribution of this work is three-fold. First, as we identify the impact of new technologies on maintenance performance, we allow envisioning the implications of I4.0 implementation combined with TPM practices. Most studies on I4.0 and maintenance performance (e.g. Jain et al., 2015; Heo et al., 2019; Ayvaz and Alpay, 2021) investigate the topic under a narrow perspective, considering the application of specific technologies in certain contexts (Zenisek et al., 2019; Silvestri et al., 2020). Our study bridges that gap by assessing the adoption level of an extensive portfolio of technologies in several manufacturing industry sectors and countries. Second, we provide evidence to underpin theoretical indications that still lack empirical validation. Third, from a practical perspective, comprehending how TPM and I4.0 interact towards more effective maintenance helps managers anticipate difficulties, set the proper expectations along with their concurrent implementation, and address countermeasures that can boost maintenance performance.

The rest of this paper is structured as follows. Section 2 provides the background on the key concepts used in this research, such as TPM, I4.0, and DIT. Section 3 develops the hypotheses investigated. Section 4 describes the adopted methodological procedures, whose results are presented in section 5 and discussed in section 6 . Section 7 concludes the article, proposing future research opportunities.

\section{Background}

\subsection{Total productive maintenance (TPM)}

The TPM approach is grounded on eight pillars (Nakajima, 1988; Jain et al., 2014): (i) autonomous maintenance, (ii) focused improvement, (iii) planned maintenance, (iv) quality 
maintenance, $(v)$ education and training, (vi) environment, health and safety, (vii) office TPM, and (viii) development management (see Figure 1). Researchers (e.g., Ahuja and Khamba, 2008a; Jain et al., 2015) claim that the joint implementation of those pillars may enhance shop floor efficiency. For instance, Gupta and Garg (2012) reported increases in efficiency between 10 and 15\% following TPM adoption, while Gupta and Vardhan (2016) indicated an efficiency increase from $56 \%$ to $86 \%$. While traditional maintenance tends to be more reactive, TPM encourages proactive involvement and communication among employees (Agustiady and Cudney, 2018). TPM also mitigates process variability, increasing its predictability and stability (Stone, 2012; Marodin and Saurin, 2013).

Figure 1 - Illustration of TPM pillars

Many authors (e.g., Shah and Ward, 2003; Furlan et al., 2011; Netland and Ferdows, 2014) have verified the positive association between TPM implementation and the firm's operational performance through suitable indicators. Overall Equipment Effectiveness (OEE) is the most widely used performance indicator for monitoring the impact of TPM implementation (McKone et al., 2001; Nallusamy and Majumdar, 2017). Defined as the product of availability, performance, and quality metrics, OEE allows a concise visualization of the process status and identification of related losses (Méndez and Rodriguez, 2017; Adesta et al., 2018). Other performance metrics have also been associated with TPM in the literature, e.g., mean-time-torepair (MTTR), mean-time-between-failures (MTBF), mean-time-to-failure (MTTF), as well as cost and safety indicators (Ahuja and Khamba, 2008a; Agustiady and Cudney, 2018; Pascal et al., 2019).

TPM implementation is carried out through practices whose timing and scope are defined by the company's readiness level and the types of problems faced (Ahuja and Khamba, 2008a; 
Jain et al., 2014). Table 1 consolidates 31 TPM practices extensively reported in the literature. Three practices stood out in terms of number of citations: $m_{1}-$ fostering operator ownership, $m_{2}-$ perform cleaning, lubricating, tightening, adjustment, inspection, readjustment on production equipment, and $m_{31}$ - maintenance improvement initiatives. All three are part of the autonomous maintenance routine, comprising activities that can be performed independently by the operators (Ahuja and Khamba, 2008b; Wickramasinghe and Perera, 2016). The adoption of autonomous maintenance has been reported in many industry sectors, characterizing its pervasiveness across contexts, e.g., automotive (Guariente et al., 2017), semiconductor (Min et al., 2011), and furniture (Miranda and Lopes, 2015). Autonomous maintenance practices are also commonly prioritized in TPM implementation (Musman and Ahmad, 2018), justifying the high citation numbers. In opposition, the least frequently mentioned practice was $m_{7}-$ groups are formed to solve specific problems, which is surprising considering the importance of assembling cross-functional teams to conduct problem-solving activities related to maintenance issues (Konecny and Thun, 2011, Sahoo, 2019). Despite differences in citation frequencies, the 31 practices in Table 1 satisfactorily represent the spectrum of TPM implementation.

Table 1 - Consolidation of main TPM practices

\subsection{Industry 4.0 (I4.0)}

I4.0 is marked by highly developed automation and digitization processes and the use of electronics and information technologies in manufacturing (Lu, 2017; Aaldering and Song, 2020). The I4.0 movement and its associated digital technologies have promoted significant and rapid changes in manufacturing environments (Salkin et al., 2018). Contemporary manufacturing challenges (e.g., the need to achieve efficiency and efficacy, complex supply 
chains, high customization, and service-oriented products, and agile and responsive markets; Llopis-Albert et al., 2021; Hopkins, 2021) have been addressed by the real-time interconnectivity among processes, products, services, and people promoted by I4.0 (Jabbour et al., 2019; Chiarini et al., 2020). Although mainly characterized by the extensive integration of disruptive technologies, the adoption of I4.0 also relies on fundamental design principles, such as decentralized decisions, information transparency, and interoperability (Hermann et al., 2016; Ghobakhloo, 2018). In that sense, I4.0 may be viewed as a socio-technical approach that encourages innovation across all organization levels (Zheng et al., 2020).

Several authors have tried to consolidate and group I4.0 technologies into sets and implementation frameworks. For instance, Fatorachian and Kazemi (2018) suggested a theoretical framework for operationalizing I4.0 in productive environments, aligned with the I4.0 implementation roadmap proposed by Ghobakhloo (2018). Frank et al. (2019) divided I4.0 technologies into front-end, representing the end-application purpose for the companies' value chain and base technologies that enable front-end technologies to be connected in a complete integrated manufacturing system. Following that proposition, Tortorella et al. (2020a) empirically validated the set of base technologies to include big data, IoT, cloud computing, and machine learning. Complementarily, Tortorella et al. (2021a) suggested grouping I4.0 technologies according to their emphasis on the companies' value streams into process- or product/service-oriented. Following Aceto et al. (2018)'s proposition of grouping I4.0 technologies according to their functionalities and roles, Tortorella et al. (2020b) proposed two bundles: ( $i$ ) sensing-communication, including technologies for data collection and transmission, and (ii) processing-actuation, including technologies that allow transforming the information previously acquired and communicated into decisions or actions needed in the processes. 
Although groupings of I4.0 technologies may vary according to the classification rationale, the portfolio of technologies covered in those studies tends to be consistent. Table 2 consolidates nine main I4.0 technologies. The most cited are $t_{2}-$ IoT, $t_{3}-$ big data, and $t_{4}-$ cloud computing, which may be justified by their crucial role in establishing a fundamental basis upon which other technologies may be developed (Frank et al., 2019; Narayanamurthy and Tortorella, 2021). In opposition, evidence on the utilization of $t_{7}$ - collaborative robots, seems scarcer although studies on its application (e.g., Heo et al., 2019; Weckenborg et al., 2019) reported a positive impact on operational performance.

Table 2 - I4.0 technologies reported in the literature

Specifically, integrating I4.0 into maintenance has been a topic of interest of researchers and practitioners. I4.0 technologies enable adopting innovative maintenance strategies and optimizing current approaches (Silvestri et al., 2020). For example, Tortorella et al. (2021b) analyzed how I4.0 has been integrated into four manufacturers from different sectors, indicating that the barriers and drivers for such integration may vary. Moreover, the use of I4.0 technologies and smart devices allows an increase in data generation, which requires further processing and analysis to support assertive maintenance decisions (Mourtzis et al., 2016). The proposed 8C architecture from Jiang (2018) is a helpful guideline to build the cyber-physical system for smart factories, focusing on both vertical and horizontal integration. That is particularly relevant to the development of maintenance activities since their effectiveness relies on the proper consideration of all organizational aspects.

\subsection{Diffusion of Innovation Theory}


The Diffusion of Innovation Theory (DIT) was first discussed in 1903 by Gabriel Tarde (Toews, 2003), who plotted the original S-shaped diffusion curve, followed by Ryan and Gross (1943), who introduced the adopter categories that were later used in the current theory popularized by Rogers (2003). DIT refers to the process of people and organizations adopting a new idea, product, practice, technology, or philosophy. Rogers (2003) argued that an initial few are open to the innovation and adopt its use in most cases. As these few early innovators "spread the word", others follow them, leading to critical mass development. Over time, the innovation becomes diffused among the population until a saturation point is achieved (Kaminski, 2011). Thus, five categories of innovation adopters were identified: (i) innovators, (ii) early adopters, (iii) early majority, (iv) late majority, and (v) laggards. There is often the addition of a sixth category called non-adopters.

Moreover, five main DIT attributes affect the rate of adoption of innovations; namely (Mustonen-Ollila and Lyytinen, 2003; Greenhalgh et al., 2004): (i) relative advantage, (ii) compatibility, (iii) complexity, (iv) trialability, and (v) observability. Relative advantage refers to the degree to which the innovation is perceived to be superior to current practice. Compatibility is the degree to which the innovation is perceived to be consistent with sociocultural values, previous ideas, and/or perceived needs. Complexity denotes the degree to which an innovation is difficult to use or understand. Trialability is the degree to which the innovation can be experienced on a limited basis. Observability refers to the degree to which the results of an innovation are visible to potential adopters.

The final results of the diffusion of innovation are its adoption, implementation, and institutionalization (Murray, 2009). An organization may (i) adopt an innovation upon the decision to acquire the innovation, (ii) implement it by putting into practice and testing it, and (iii) institutionalize it by fully incorporating it into the organizational routines (Oldenburg et al., 1999; Dusenbury and Hansen, 2004). There is also another potential outcome from the 
diffusion of innovation, which is the 'failed diffusion'. It refers to the diffusion of an innovation that was not fully adopted due to its weaknesses, competition from other innovations, or simply a lack of awareness (Rogers, 2003).

\section{Hypotheses development}

The integration of I4.0 into maintenance might be facilitated by the active collaboration between production and maintenance staff (Rødseth et al., 2017), enabling to move from breakdown and periodic maintenance to predictive and proactive maintenance policies (Mosyurchak et al., 2017). That helps optimize maintenance scheduling by detecting machine weaknesses at an early stage (Felsberger et al., 2020). I4.0 technologies are expected to support the adoption of innovative maintenance approaches, capitalizing on current practices. For instance, data analytics and maintenance simulations might improve planning and the prediction of components lifecycle stages. At the same time, augmented reality could provide clearer guidance for diagnosing and inspecting machines (Silvestri et al., 2020). Moreover, disruptive I4.0 technologies, such as IoT and cloud computing, may enable the effective monitoring of operating conditions leading to more assertive decisions on the equipment (Mourtzis and Vlachou, 2018; Zheng et al., 2020).

However, Palmarini et al. (2018) emphasized that some technical issues still prevent I4.0 technologies (e.g., augmented reality) from being adopted in industrial applications. Realworld implementations are still rare due to the lack of high-quality monitoring data and little practical experience with I4.0 (Zenisek et al., 2019) which might undermine the perception of their benefits on maintenance activities (Frank et al., 2019). The high complexity, automation, and flexibility of an intelligent factory bring new challenges to reliability and safety engineers (Yan et al., 2017), who must integrate I4.0 into existing maintenance practices aiming at higher 
equipment performance and availability. Those aspects raise doubts about the effects of I4.0 technologies on maintenance performance and their smooth integration with existing maintenance practices.

As pointed out by Sahin (2006), many studies on DIT involve technological innovations, such that the word "technology" is commonly used as a synonym of "innovation". Those studies also stress the importance of communication and peer networking within the adoption process (Kaminski, 2011). In that framing, when individuals do not (or poorly) identify the DIT attributes in a technology, its adoption rate is likely to be compromised. Despite I4.0's growing understanding, Fettermann et al. (2018) and Tortorella et al. (2021b) argued that academics and practitioners still present difficulties grasping its concepts. As integrating I4.0 technologies into manufacturers is an innovative process (Lorenz et al., 2020), it is subjected to the innovation uncertainties posited by DIT, which may occur regardless of the company's maturity in terms of existing management approaches, such as TPM. Against this backdrop and to better investigate the role performed by I4.0 technologies in maintenance improvement, we formulated the following hypotheses:

$H_{1}$ : The adoption of 14.0 technologies positively impacts maintenance performance.

$\mathrm{H}_{2}$ : The adoption of I4.0 technologies positively moderates the impact of TPM practices on maintenance performance.

\section{Method}

We adopted an empirical approach to acquiring knowledge via direct/indirect observation or experience (Goodwin, 2005). We collected data through a survey-based method due to its high level of representativeness, low cost, potential statistical relevance, and standardized stimulus to all respondents (Montgomery, 2013). The quantification of empirical evidence gathered 
from respondents that satisfy pre-determined selection criteria is a procedure frequently reported in similar research (e.g., Marodin et al., 2018; Li et al., 2019). The proposed method consists of four main steps (see Figure 2): (i) sample selection and data collection; (ii) instrument development; (iii) constructs' validity and reliability; and (iv) data analysis. Details of those steps are subsequently provided.

Figure 2 - Steps of the proposed method

\subsection{Sample selection and data collection}

A transnational survey was conducted with respondents from fifteen countries: Brazil, Chile, Mexico, Argentina, Uruguay, Spain, Italy, Australia, Kuwait, Oman, United Arabia Emirates, Saudi Arabia, India, Morocco, and Qatar. As suggested by Bhaskaran and Sukumaran (2007) and Kull et al. (2014), national culture may influence not only the management practices companies tend to adopt but also their extension, justifying the diversity of countries sampled. A non-random approach was followed for collecting the data from respondents that met preestablished selection criteria (Smith, 1983).

First, we targeted practitioners who worked in medium- and large-sized manufacturing companies that have already implemented TPM and initiated the adoption of I4.0 technologies. Second, respondents should belong to maintenance departments or departments that directly relate to maintenance activities in their companies (e.g., production and engineering), visualizing and understanding the specificities related to maintenance practices. Third, due to the broad scope of both TPM and I4.0 approaches, we aimed at respondents from different organizational levels, i.e., operational (e.g., technicians, analysts, and engineers), tactical (e.g., supervisors and coordinators), and strategic (e.g., managers and directors). Such a requirement 
should provide a more holistic perception of the implementation of both TPM and I4.0. Considering the scattered pervasiveness of both approaches across the industrial spectrum, we did not focus our data collection on a specific industry sector, which is a common approach in studies of similar nature (e.g., Marodin et al., 2016; Tortorella and Fettermann, 2018).

Data collection occurred during March and April 2021 and was conducted by leading researchers from the selected regions. Access to companies was facilitated by an existing network established by the authors and used in previous research activities and studies, increasing the response rate. This experienced group of authors has been collaborating in industry-oriented research over the last decades, enabling the development of an extensive network. Each author used their contacts to send the questionnaire electronically or physically, depending on preferences and convenience. An invitation email was sent to potential respondents instructing them to gauge answers to match their level of knowledge on TPM practices and I4.0 technologies, such that blank answers would denote insufficient knowledge about the items presented. It was indicated in the invitation that participation was voluntary and anonymous and that there were no wrong answers. In total, 1,353 practitioners were contacted, 318 of which provided full responses, leading to a $23.5 \%$ response rate, higher than the usual $15 \%$ rate typical of survey-based studies, according to Hair et al. (2014). Nonresponse bias was checked using Armstrong and Overton's (1977) procedure. To assess differences in early and late responses collected in March $(\mathrm{n} 1=129)$ and April $(\mathrm{n} 2=189)$, respectively, we used Levene's test for the equality of variances and a t-test for the equality of means. No significant differences were found in the means and variances of the two groups.

Appendix A gives a complete overview of the sample's characteristics. There is a predominance of respondents from emerging economies $(76.7 \%), 52.2 \%$ of them working for large-sized companies (> 500 employees), $74.8 \%$ with more than five years of work experience. $31.8 \%$ of the respondents were technicians, analysts, or engineers, $25.8 \%$ were supervisors or 
coordinators, and $42.4 \%$ were managers or directors. $50.6 \%$ of the companies have been implementing TPM for more than five years. Particularly regarding the company's technology intensity, Tortorella et al. (2021a) suggested that this variable may positively influence I4.0 adoption. Hence, we classified respondents into two categories based on the technology intensity of the industry sectors to which they belong, as indicated by the Organization for Economic Cooperation and Development (OECD) (2011): (i) high and medium-high, and (ii) low and medium-low. $50.3 \%$ of the respondents belonged to industry sectors with low and midlow technology intensity.

\subsection{Instrument development}

The questionnaire had four parts (see Appendix B), as follows:

- Part 1: we collected data on respondents and their respective companies, allowing identifying the sample's demographic profile;

- Part 2: we asked respondents to score the adoption level of the 31 TPM practices listed in Table 1 in their companies using a five-point scale, in which 1 indicated 'no adoption' and 5' full adoption';

- Part 3: we asked respondents to score the adoption level of the 9 I4.0 technologies listed in Table 2 in their companies using the same scale of part 2. Although acknowledging that the concept of I4.0 transcends the strict integration of novel technologies, we used them as a proxy for I4.0 implementation, which is a common approach in studies on the subject (e.g., Dalenogare et al., 2018; Rossini et al., 2019); and

- Part 4: respondents were asked to evaluate their companies' performance improvement in the last two years using a 5-point Likert scale varying from 1 (significantly worsened) to 5 (significantly improved), with 3 denoting the neutral situation. Since TPM implementation tends to be directly related to maintenance performance, six 
interrelated indicators were used in part 4, as suggested by McKone et al. (2001), Ahuja and Khamba (2008a), Nallusamy and Majumdar (2017), Agustiady and Cudney (2018), and Pascal et al. (2019); they are MTTR, MTBF, MTTF, OEE, cost, and safety (injuries and work accidents). Variations in performance are easier to be assessed by respondents, and using such information increases the validity of responses (Tortorella et al., 2019).

Four academic experts on I4.0 and TPM pre-assessed the questionnaire to verify its face and content validity, as suggested by Kothari (2004). Minor corrections in taxonomy were suggested for increased clarity of items. As we collected data utilizing psychometric scales, common method variance could be an issue (Huber and Power, 1985). Some countermeasures were addressed to prevent that. Regarding the questionnaire design, dependent variables were presented far from independent variables (Podsakoff and Organ, 1986), and anonymity and confidentiality of the study were announced beforehand to participants, who were also informed that there were no wrong answers (Podsakoff et al., 2003). Regarding statistical checks, Harman's single-factor test was performed utilizing all study variables (Malhotra et al., 2006), resulting in a first factor explaining $29.5 \%$ of the total variance. This test evidenced that no single factor accounted for most of the variance in responses; hence, common method bias was disregarded.

\subsection{Constructs' validity and reliability}

We performed three Exploratory Factor Analyses (EFAs) using Principal Component (PC) extraction to identify constructs based on the collected responses (Fabrigar et al., 1999). The utilization of EFA is indicated when there are no a priori hypotheses about components or patterns in the items measured (Finch and West, 1997). 
The first EFA was carried out on the maintenance performance indicators (dependent variable). Using a Varimax rotation, we obtained the first PC (with an associated eigenvalue of 3.148 and accounting for $52.47 \%$ of the total variance) with all loadings greater than 0.45 (Hair et al., 2014), as displayed in Table 3. Construct reliability was tested through Cronbach's alpha, which resulted in 0.823 for the construct, and indicated high reliability in responses (Meyers et al., 2006).

Table 3 - EFA to validate the maintenance performance construct

The second EFA was carried out using responses on the adoption level of the 31 TPM practices to identify TPM constructs. After rotating the axes using Varimax, the analysis resulted in four components with associated eigenvalues greater than 1.0 and accounting for $53.68 \%$ of the total variance. The analysis was replicated using an oblique rotation of axes to test orthogonality, resulting in similar components. Cronbach's alpha values for all four constructs were greater than 0.6 (Meyers et al., 2006), confirming the reliability of responses. We excluded four practices whose factor loadings did not meet the 0.45 threshold (Hair et al., 2014) in any of the components. The remaining factor loadings indicated four practices' constructs (independent variables), as shown in Table 4. They were labeled according to their application focus and corresponding TPM pillar.

The first construct grouped practices oriented to improving quality (e.g., $m_{14}$-achieving zero defects) and effectively incorporating lessons learned into the development of new systems (e.g., $m_{30}-$ utilizing learning from existing systems to new systems). According to Nakajima (1988), two TPM pillars present those roles: $(i)$ quality maintenance and (ii) development management, respectively. Hence, the first construct was labeled 'quality and development 
maintenance' (QDM). The second construct grouped practices related to planned maintenance (e.g., $m_{11}$ - establishing preventive maintenance check sheets) and focused improvements (e.g., $m_{5}$ - systematic identification and elimination of losses), which represent two TPM pillars (Adesta et al., 2018). Thus, the second construct was labeled 'planned and focused maintenance' (PFM). Since the third construct mainly grouped practices focused on improving the safety, health, and environment (e.g., $m_{21}-$ ensuring safe working environment, and $m_{23}-$ eliminating incidents of injuries and accidents), it was labeled 'environment, health, and safety maintenance' (EHSM). The fourth construct grouped practices that foster employees to autonomously perform inspections, lubrication, and minor repairs in their equipment (e.g., $m_{2}$ - perform cleaning, lubricating, tightening, adjustment, inspection, readjustment on production equipment) by enhancing their abilities and technical expertise (e.g., $m_{20}$ - periodic skill evaluation and updating). Practices in the construct corroborate with concepts inherent to the TPM pillar 'autonomous maintenance' (AM) (Jain et al., 2014); hence, it was labeled as such.

Table 4 - EFA to validate the TPM constructs

The last EFA was carried out using responses on the adoption level of the nine I4.0 technologies presented in the questionnaire. Similar to previous EFAs, we used a Varimax rotation to identify the number of PCs with eigenvalues larger than 1.0. As shown in Table 5, two components (with associated eigenvalues of 3.647 and 1.367) were identified, accounting for $55.7 \%$ of the total variance. We replicated the analysis performing an oblique rotation for orthogonality verification, extracting similar components. Since their associated Cronbach's alpha values were above 0.6 , reliability was ensured. Constructs were named based on the analysis of factor loadings. As I4.0 technologies were grouped similarly to the proposition in Tortorella et al. (2020b), we adopted their proposed labels: (i) 'sensing-communication' 
(SENS_COMM) for the construct grouping technologies aiming at data collection and sharing (e.g., wireless sensors and cloud computing), and 'processing and actuation' (PROC_ACT) for the construct grouping technologies that process information and control systems based on this information.

Table 5 - EFA to validate the I4.0 constructs

\subsection{Data analysis}

In this step, Ordinary Least Squares (OLS) hierarchical linear regression models were obtained to examine the hypotheses initially formulated and displayed in section 3. In OLS, unknown parameters of a linear regression model are estimated using a linear least-squares method. OLS determines the parameters associated with the explanatory variables of a linear function by the principle of least squares, i.e., minimizing the sum of the squares of the differences between the observed values of the dependent variable and those predicted by the linear function of the independent variable (Myers and Myers, 1990). A simple formula can express the resulting estimators.

Input variables corresponded to the EFAs' constructs, such that the weighted average of original responses for the items in each construct was calculated using their corresponding factor loadings as weights. The resulting outcomes were standardized. That also allowed to report the unstandardized coefficients of the regression models since they represent a standardized effect (Goldsby et al., 2013). Multicollinearity was also checked by determining the variance inflation factors (VIF) associated with each variable; all VIF values were below the threshold of 5.0 (Belsley et al., 2005). 
Three regression models were tested, always using maintenance performance as the dependent variable. In Model A, maintenance performance was regressed on the four control variables (socioeconomic context, technology intensity of the industry sector, company size, and time of TPM adoption). Model B included the direct effect of the independent variables, i.e., the two I4. 0 constructs and the four TPM constructs. In Model C, we added the moderating effects of the two I4.0 technologies (interaction terms). All models were initially tested using dummy variables for industry sector and country since they may influence the readiness level of both I4.0 and TPM. Their coefficients were not significant, and they were removed from the models in Table 6.

Following Hair et al.'s (2014) indications, we performed normality, linearity, and homoscedasticity checks. Normality of the error term distribution was verified using the Kolmogorov Smirnov test, resulting in $p$-values $>0.05$ for all models. Linearity was verified using plots of the partial regression for each model. Finally, the standardized residuals were plotted against the predicted values allowing the visual examination of homoscedasticity. All procedures confirmed the necessary conditions for the OLS regression analyses.

\section{Results}

Table 6 presents the $\hat{\beta}$ coefficients of the OLS regression models. Although all three models were significant, adding both the independent variables and the interaction terms (Model C) enhanced the prediction capacity of maintenance performance improvement. When compared to Models A and B, Model C presented an important change in the $R^{2}$ value, explaining $41.4 \%$ of the variance in the dataset $(F$-value $=11.468 ; p$-value $<0.01)$. In model $\mathrm{C}$, no control variable displayed a significant effect on the perceived improvement of maintenance performance. Similarly, SENS_COMM and QDM displayed no significant direct effects. In 
opposition, four independent variables displayed significant positive direct effects; they are: PROC_ACT $(\hat{\beta}=0.215 ; p$-value $<0.01), \operatorname{AM}(\hat{\beta}=0.241 ; p$-value $<0.01), \operatorname{PFM}(\hat{\beta}=0.150 ; p$ value $<0.10)$, and $\operatorname{EHSM}(\hat{\beta}=0.155 ; p$-value $<0.05)$. As we found a positive association between PROC_ACT technologies and maintenance performance, we argue that $H_{1}$ was partially supported.

Regarding the moderating effects of I4.0 technologies on the relationship between TPM practices and maintenance performance improvement, we identified two significant interactions: $(i)$ PFM and SENS_COMM $(\hat{\beta}=-0.132 ; p$-value $<0.10)$, and (ii) EHSM and SENS_COMM $(\hat{\beta}=0.206 ; p$-value $<0.01)$. Although SENS_COMM did not display a significant direct effect, the technologies in the construct appear to have an important role as moderators of certain TPM practices. In fact, we found that the moderation varies (i.e., displaying positive and negative effects) depending on the TPM construct, as illustrated in Figure 3, partially supporting $\mathrm{H}_{2}$. Overall, some of our results converged to expectations, while others contradicted previous studies. Both are worth discussing. Figure 4 summarizes the relationships empirically verified in our study.

Table $6-\hat{\beta}$ coefficients for hierarchical regression analyses

Figure 3 - Moderation of SENS_COMM technologies on the effect of EHSM and PM practices on maintenance performance

Figure 4 - Empirically validated relationships 


\section{Discussion}

The direct effect of SENS_COMM on maintenance performance was not significant in Model $\mathrm{C}$, which was somewhat surprising. The amount of data collected from production processes has significantly increased due to the wide utilization of sensing technologies (Sun et al., 2021). When processed and analyzed, such data may be transformed into valuable information and knowledge (Carvalho et al., 2019). SENS_COMM technologies allow data acquisition and transmission, interconnecting people, materials, and equipment (Tortorella et al., 2020b), although not necessarily implying action-taking. As such, SENS_COMM technologies are likely to be facilitators of other activities, such as predictive maintenance planning (Civerchia et al., 2017; Ayvaz and Alpay, 2021) and risk assessments (Takeda et al., 2016; Lai et al., 2019), which use data to support decisions and actions. That converges to indications from Rogers' (2003) DIT, namely that technologies that serve as the information base for decisions tend to display a lower level of observability (i.e., visibility of innovation results to others), which may impair their adoption rate. Such lower observability may justify why SENS_COMM presented a more prominent moderating role instead of directly affecting maintenance performance.

Despite the lack of direct impact, our findings indicated that SENS_COMM technologies have a relevant moderating role in the relationship between I4.0 and maintenance performance; however, this role varied. While the interaction between SENS_COMM and EHSM positively affected maintenance performance (as initially hypothesized in $\mathrm{H}_{2}$ ), SENS_COMM technologies negatively moderate the effect of PFM. An explanation for such contradictory results may be associated with the findings from Carvalho et al. (2019), who suggested that the effect of sensing technologies on maintenance is highly dependent on their appropriate choice and application. SENS_COMM technologies allow acquiring and communicating large 
amounts of data, which sometimes may overload decision-makers lacking the proper competencies to interpret them, creating additional layers of uncertainty and leading to misguided decisions. Wan et al. (2017) emphasized that PFM tasks in the context of I4.0 still impose challenges, such as the efficient analysis of real-time planned maintenance, active prediction of equipment's service life, and early problems' detection. SENS_COMM technologies allow a better understanding of abnormal behaviors in production systems, which is fundamental for adopting a proactive maintenance approach instead of conventional timebased strategies prescribed by PFM (Santos et al., 2015). That leads to a paradigm change towards condition-based maintenance (CBM), as decisions are now based on the use of a large, diverse, and dynamic dataset to optimize operational costs (Ahmad and Kamaruddin, 2012). The shift to CBM could be perceived as reducing the compatibility attribute of SENS_COMM technologies (i.e., the degree to which an innovation is perceived as consistent with the existing values, past experiences, and needs of potential adopters; Rogers, 2003), thereby justifying the negative moderation effect.

The positive direct effect of PROC_ACT technologies (e.g., 3D printing, collaborative robots, machine/deep learning, and augmented reality) on maintenance performance is aligned with the literature. According to Tortorella et al. (2020b), PROC_ACT comprises technologies that enable transforming the information previously acquired and communicated into decisions or actions required. Similarly, PROC_ACT technologies may be seen as the "hardware" component of I4.0, which according to Rogers (2003), is the tool that embodies the technology in the form of a material or physical object. Each PROC_ACT technology may have a different impact on maintenance performance. For instance, Asfour et al. (2018) reported utilizing collaborative robots to perform complex and risky maintenance activities in industrial environments in parallel with human workers, improving their safety. Wits et al. (2016) claimed that 3D printing (or additive manufacturing) could significantly reduce the design and 
production times for customized spare parts for maintenance, entailing cost reduction and a potentially lower MTTR. Mourtzis et al. (2020) developed a framework for supporting remote maintenance and repair operation based on augmented reality, reducing MTTR and consequently improving OEE. Our results corroborate those findings.

PROC_ACT technologies display a significant direct effect on maintenance performance but no significant moderating effects. This outcome contradicts previous works that viewed PROC_ACT technologies, such as machine learning (Susto et al., 2014; Zenisek et al., 2019; Kaparthi and Bumblauskas, 2020), as support to maintenance activities. Our result may be justified by the DIT's concept of relative advantage (i.e., the degree to which an innovation is perceived as being better than the idea it supersedes; Sahin, 2006) and the categorization of innovations. For Rogers (2003), relative advantage is the strongest predictor of an innovation's adoption rate. Unlike preventive innovations, whose relative advantage is highly uncertain, incremental innovations (e.g., the adoption of PROC_ACT technologies) provide beneficial outcomes quickly. This prominent short-term effect of PROC_ACT technologies on maintenance performance may override their perception as moderators, undermining the identification of any significant interaction with TPM practices.

\section{Conclusions}

This research investigated the effect of I4.0 technologies on the relationship between TPM practices and maintenance performance. We found that I4.0 technologies present both direct and moderating effects on the improvement of maintenance performance. However, the extension of those effects varies depending on the TPM practices and I4.0 technologies involved, which is in line with the Diffusion of Innovations theory (DIT). Our results present implications for both theory and practice. 
In theoretical terms, this investigation contributes to understanding the role of I4.0 for maintenance performance improvement. The examination of how new technologies derived from I4.0 influence existing TPM practices is still underexplored. DIT provides a valuable theoretical lens to bridge that gap. We brought empirical evidence to support the analysis of relationships between TPM and I4.0, explained in light of DIT. We argued that technologies' characteristics related to some innovation attributes might determine the success of the integration between TPM and I4.0. More specifically, the extent of the moderating role of I4.0 on the relationship between TPM and maintenance performance appears to be mainly affected by the perceptions related to the relative advantage, compatibility, and observability of I4.0 technologies. Ensuring that those attributes are properly perceived seems key to favoring a positive moderation of I4.0 technologies. Our study provides initial evidence towards the digitalization of TPM practices. We are not aware of similar studies on this subject, highlighting a unique contribution of this research.

In practical terms, our research showed that the joint implementation of TPM and I4.0 might lead to higher maintenance performance. That is especially true when combining TPM practices focused on the environment, health, and safety with I4.0 technologies that aim to sense and communicate data across the organization. We found that not all interactions between TPM and I4.0 significantly and positively impact maintenance performance, gauging managers' expectations regarding the integration of I4.0 technologies into TPM practices and allowing the prioritization of efforts and anticipation of potential problems. Moreover, the negative effect of the interaction between sensing and communication technologies and planned and focused maintenance practices highlights the need in companies to adapt their existing practices to achieve superior results (e.g., shifting from a conventional time-based planned maintenance to a proactive real-time approach). In other words, the successful digitalization of TPM is not just a matter of incorporating new technologies into current 
practices; it also relies on the revision of existing practices to be properly adapted to cope with the advantages raised by the Fourth Industrial Revolution.

We close by pointing out some of our study's limitations. The first relates to the usual limitations of single-respondent survey research. Although working with a large sample size and taking measures to mitigate issues related to common method bias, we suggest future empirical studies to test the effects of I4.0 on the relationship between TPM and maintenance performance using datasets with multiple respondents per company. Second, opinion-based surveys are intrinsically limited by data subjectivity. Thus, examining the identified relationships based on actual maintenance performance data would be a promising opportunity for future research. Third, we empirically proposed multi-item constructs for both TPM and I4.0 using the items listed in the questionnaire. Nevertheless, we acknowledge that multi-layer and more complete measurement instruments could lead to the identification of complementary constructs, allowing a more holistic view of the investigated relationships. Future studies could expand our data collection instrument, potentially identifying relationships with and between other TPM and I4.0 constructs.

\section{References}

Aaldering, L., \& Song, C. (2020), "Of leaders and laggards-Towards digitalization of the process industries", Technovation, 102211.

Aceto, G., Persico, V., \& Pescapé, A. (2018), "The role of Information and Communication Technologies in healthcare: taxonomies, perspectives, and challenges", Journal of Network and Computer Applications, Vol.107, pp.125-154.

Adesta, E., Prabowo, H., \& Agusman, D. (2018), "Evaluating 8 pillars of Total Productive Maintenance (TPM) implementation and their contribution to manufacturing performance", In IOP Conference Series: Materials Science and Engineering (Vol.290, No.1, p.012024). IOP Publishing. 
Agustiady, T., \& Cudney, E. (2018), "Total productive maintenance", Total Quality Management \& Business Excellence, (forthcoming).

Ahmad, R., \& Kamaruddin, S. (2012), "An overview of time-based and condition-based maintenance in industrial application", Computers \& Industrial Engineering, Vol.63 No.1, pp.135-149.

Ahuja, I., \& Khamba, J. (2008a), "Justification of total productive maintenance initiatives in Indian manufacturing industry for achieving core competitiveness", Journal of Manufacturing Technology Management, Vol.19 No.5, pp.645-669.

Ahuja, I., \& Khamba, J. (2008b), "Total productive maintenance: literature review and directions", International Journal of Quality \& Reliability Management, Vol.25 No.7, pp.709-756.

Al-Najjar, B., Algabroun, H., \& Jonsson, M. (2018), "Maintenance 4.0 to fulfil the demands of Industry 4.0 and Factory of the Future", International Journal of Engineering Research and Applications, Vol.8 No.11, pp.20-31. Armstrong, J., \& Overton, S. (1977), "Estimating nonresponse bias in mail surveys", Journal of Marketing Research, Vol.14 No.3, pp.396-402.

Asfour, T., Kaul, L., Wächter, M., Ottenhaus, S., Weiner, P., Rader, S., ... \& Haubert, H. (2018), "Armar-6: A collaborative humanoid robot for industrial environments", In 2018 IEEE-RAS 18th International Conference on Humanoid Robots (Humanoids) (pp.447-454). IEEE.

Ayvaz, S., \& Alpay, K. (2021), "Predictive maintenance system for production lines in manufacturing: A machine learning approach using IoT data in real-time", Expert Systems with Applications, Vol.173, pp.114598.

Belsley, D., Kuh, E., \& Welsch, R. (2005), Regression diagnostics: identifying influential data and sources of collinearity, John Wiley \& Sons, London.

Bhaskaran, S. \& Sukumaran, N. (2007), "National culture, business culture and management practices: consequential relationships?", Cross Cultural Management: An International Journal, Vol.14 No.1, pp.54-67.

Bokrantz, J., Skoogh, A., Berlin, C., \& Stahre, J. (2017), "Maintenance in digitalised manufacturing: Delphi-based scenarios for 2030", International Journal of Production Economics, Vol.191, pp.154-169.

Bokrantz, J., Skoogh, A., Berlin, C., Wuest, T., \& Stahre, J. (2020), "Smart Maintenance: a research agenda for industrial maintenance management", International Journal of Production Economics, Vol.224, pp.107547. 
Carvalho, T., Soares, F., Vita, R., Francisco, R., Basto, J., \& Alcalá, S. (2019), "A systematic literature review of machine learning methods applied to predictive maintenance", Computers \& Industrial Engineering, Vol.137, pp. 106024.

Chiarello, F., Trivelli, L., Bonaccorsi, A., \& Fantoni, G. (2018), "Extracting and mapping industry 4.0 technologies using Wikipedia", Computers in Industry, Vol.100, pp.244-257.

Chiarini, A., Belvedere, V., \& Grando, A. (2020), "Industry 4.0 strategies and technological developments. An exploratory research from Italian manufacturing companies", Production Planning \& Control, Vol.31 No.16, pp.1385-1398.

Chirumalla, K. (2021), "Building digitally-enabled process innovation in the process industries: A dynamic capabilities approach", Technovation, 102256.

Civerchia, F., Bocchino, S., Salvadori, C., Rossi, E., Maggiani, L., \& Petracca, M. (2017), "Industrial Internet of Things monitoring solution for advanced predictive maintenance applications", Journal of Industrial Information Integration, Vol.7, pp.4-12.

Coleman, C., Damodaran, S., Chandramouli, M., \& Deuel, E. (2017), "Making maintenance smarter: Predictive maintenance and the digital supply network", Deloitte Insights.

Cua, K.O., McKone, K.E., \& Schroeder, R.G. (2001), "Relationships between implementation of TQM, JIT, and TPM and manufacturing performance", Journal of Operations Management, Vol.19 No.6, pp.675-694.

Dalenogare, L., Benitez, G., Ayala, N., \& Frank, A. (2018), "The expected contribution of Industry 4.0 technologies for industrial performance", International Journal of Production Economics, Vol.204, pp.383-394.

Dusenbury, L., \& Hansen, W.B. (2004), "Pursuing the course from research to practice", Prevention Science, Vol.5 No.1, pp.55-59.

Fabrigar, L., Wegener, D., MacCallum, R., \& Strahan, E. (1999), "Evaluating the use of exploratory factor analysis in psychological research", Psychological Methods, Vol.4 No.3, pp.272.

Fatorachian, H., \& Kazemi, H. (2018), "A critical investigation of Industry 4.0 in manufacturing: theoretical operationalisation framework", Production Planning \& Control, Vol.29 No.8, pp.633-644. 
Felsberger, A, Qaiser, F., Choudhary, A. \& Reiner, G. (2020), "The impact of Industry 4.0 on the reconciliation of dynamic capabilities: evidence from the European manufacturing Industries", Production Planning \& Control, (forthcoming).

Fettermann, D., Cavalcante, C., Almeida, T., \& Tortorella, G. (2018), "How does Industry 4.0 contribute to operations management?", Journal of Industrial and Production Engineering, Vol.35 No.4, pp.255-268.

Frank, A., Dalenogare, L., \& Ayala, N. (2019), "Industry 4.0 technologies: Implementation patterns in manufacturing companies" International Journal of Production Economics, Vol.210, pp.15-26.

Finch, J., \& West, S. (1997), "The investigation of personality structure: Statistical models", Journal of Research in Personality, Vol.31 No.4, pp.439-485.

Furlan, A., Vinelli, A., \& Dal Pont, G. (2011), "Complementarity and lean manufacturing bundles: an empirical analysis", International Journal of Operations \& Production Management, Vol.31 No.8, pp.835-850.

Ghobakhloo, M. (2018), "The future of manufacturing industry: a strategic roadmap toward Industry 4.0", Journal of Manufacturing Technology Management, Vol.29 No.6, pp.910-936.

Goldsby, T., Michael Knemeyer, A., Miller, J., \& Wallenburg, C. (2013), "Measurement and moderation: finding the boundary conditions in logistics and supply chain research", Journal of Business Logistics, Vol.34 No.2, pp.110-116.

Goodwin, C. (2005), Research in Psychology: methods and design, John Wiley \& Sons, Inc., New York.

Greenhalgh, T., Robert, G., Macfarlane, F., Bate, P., \& Kyriakidou, O. (2004), "Diffusion of innovations in service organizations: systematic review and recommendations", The Milbank Quarterly, Vol.82 No.4, pp.581-629.

Guariente, P., Antoniolli, I., Ferreira, L., Pereira, T., \& Silva, F. (2017), "Implementing autonomous maintenance in an automotive components manufacturer", Procedia Manufacturing, Vol.13, pp.1128-1134.

Gupta, A.K., \& Garg, R.K. (2012), "OEE improvement by TPM implementation: a case study", International Journal of IT, Engineering and Applied Sciences Research, Vol.1 No.1, pp.115-124.

Gupta, P., \& Vardhan, S. (2016), "Optimizing OEE, productivity and production cost for improving sales volume in an automobile industry through TPM: a case study", International Journal of Production Research, Vol54 No.10, pp.2976-2988. 
Hair, J., Black, W., Babin, B. \& Anderson, R. (2014), Multivariate Data Analysis, Pearson New International Edition (Seventh edition), Harlow, Essex, Pearson.

Heo, Y., Kim, D., Lee, W., Kim, H., Park, J., \& Chung, W. (2019), "Collision detection for industrial collaborative robots: A deep learning approach", IEEE Robotics and Automation Letters, Vol.4 No.2, pp.740-746.

Hermann, M., Pentek, T., \& Otto, B. (2016), "Design principles for industrie 4.0 scenarios", In 2016 49th Hawaii International Conference on System Sciences (HICSS) (pp.3928-3937). IEEE.

Hopkins, J. (2021), "An investigation into emerging industry 4.0 technologies as drivers of supply chain innovation in Australia", Computers in Industry, Vol.125, pp.103323.

Huber, G., \& Power, D. (1985), "Retrospective reports of strategic-level managers: guidelines for increasing their accuracy", Strategic Management Journal, Vol.6, pp.171-180.

IBM (2017). The evolution of maintenance. Available at: https://www.ibm.com/blogs/internet-ofthings/maintenance-evolution-prescriptive/ (accessed on November 17 $7^{\text {th }} 2021$ ).

Ighravwe, D., \& Oke, S. (2020), "Sustenance of zero-loss on production lines using Kobetsu Kaizen of TPM with hybrid models", Total Quality Management \& Business Excellence, Vol.31 No.1-2, pp.112-136.

Jabbour, C.J.C., de Sousa Jabbour, A.B.L., Sarkis, J., \& Godinho Filho, M. (2019), "Unlocking the circular economy through new business models based on large-scale data: An integrative framework and research agenda", Technological Forecasting and Social Change, Vol.144, pp.546-542.

Jain, A., Bhatti, R., \& Singh, H. (2015), "OEE enhancement in SMEs through mobile maintenance: a TPM concept", International Journal of Quality \& Reliability Management, Vol.32 No.5, pp.503-516.

Jain, A., Bhatti, R. \& Singh, H. (2014), "Total productive maintenance (TPM) implementation practice: A literature review and directions", International Journal of Lean Six Sigma, Vol.5 No.3, pp.293-323.

Jiang, J.R. (2018), "An improved cyber-physical systems architecture for Industry 4.0 smart factories", Advances in Mechanical Engineering, Vol.10 No.6, pp.1687814018784192.

Kaminski, J. (2011), "Diffusion of innovation theory", Canadian Journal of Nursing Informatics, Vol.6 No.2, pp.1-6. 
Kaparthi, S., \& Bumblauskas, D. (2020), "Designing predictive maintenance systems using decision tree-based machine learning techniques", International Journal of Quality \& Reliability Management, Vol.37 No.4, pp.659686.

Kayikci, Y., Subramanian, N., Dora, M., \& Bhatia, M. (2020), "Food supply chain in the era of Industry 4.0: blockchain technology implementation opportunities and impediments from the perspective of people, process, performance, and technology", Production Planning \& Control, (forthcoming).

Klathae, V., \& Ruangchoengchum, P. (2019), "The Predictable Maintenance 4.0 by Applying Digital Technology: A Case Study of Heavy Construction Machinery", Review of Integrative Business and Economics Research, Vol.8, pp.34-46.

Konecny, P., \& Thun, J. (2011), "Do it separately or simultaneously-An empirical analysis of a conjoint implementation of TQM and TPM on plant performance", International Journal of Production Economics, Vol.133 No.2, pp.496-507.

Kothari, C. (2004), Research methodology: Methods and techniques, New Age International.

Kull, T., Yan, T., Liu, Z., \& Wacker, J. (2014), "The moderation of lean manufacturing effectiveness by dimensions of national culture: testing practice-culture congruence hypotheses", International Journal of Production Economics, Vol.153, pp.1-12.

Lai, C., Jiang, W., \& Jackson, P. (2019), "Internet of Things enabling condition-based maintenance in elevators service", Journal of Quality in Maintenance Engineering, Vol.25 No.4, pp.563-588.

Lasi, H., Fettke, P., Kemper, H., Feld, T., \& Hoffmann, M. (2014), "Industry 4.0", Business \& Information Systems Engineering, Vol.6 No.4, pp.239-242.

Li, Y., Sawhney, R., \& Tortorella, G. (2019), "Empirical Analysis of Factors Impacting Turnover Intention among Manufacturing Workers", International Journal of Business and Management, Vol.14 No.4, pp.1-18.

Llopis-Albert, C., Rubio, F., \& Valero, F. (2021), "Impact of digital transformation on the automotive industry", Technological Forecasting and Social Change, Vol.162, pp.120343.

Lorenz, R., Benninghaus, C., Friedli, T., \& Netland, T. (2020), "Digitization of manufacturing: the role of external search", International Journal of Operations \& Production Management, Vol.40 No.7/8, pp.1129-1152. 
Lu, Y (2017), "Industry 4.0: A Survey on Technologies. Applications and Open Research Issues", Journal of Industrial Information Integration, Vol.6 No.1, pp.1-10.

Malhotra, N., Birks, D., \& Wills, P. (2006), Marketing research: an applied approach, Pearson Education, London.

Marodin, G., Frank, A. \& Tortorella, G. (2016), "Contextual factors and lean production implementation in the Brazilian automotive supply chain", Supply Chain Management: An International Journal, Vol.21 No.4, pp.417432.

Marodin, G., Frank, A., Tortorella, G., \& Netland, T. (2018), "Lean product development and lean manufacturing: Testing moderation effects", International Journal of Production Economics, Vol.203, pp.301-310.

Marodin, G., \& Saurin, T. (2013), "Implementing lean production systems: research areas and opportunities for future studies", International Journal of Production Research, Vol.51 No.22, pp.6663-6680.

McKone, K.E., Schroeder, R.G., \& Cua, K.O. (2001), "The impact of total productive maintenance practices on manufacturing performance", Journal of Operations Management, Vol.19 No.1, pp.39-58.

Méndez, J., \& Rodriguez, R. (2017), "Total productive maintenance (TPM) as a tool for improving productivity: a case study of application in the bottleneck of an auto-parts machining line", The International Journal of Advanced Manufacturing Technology, Vol.92 No.1, pp.1013-1026.

Meyers, L., Gamst, G., \& Guarino, A. (2006), Applied multivariate research, Sage Publications, Thousand Oaks.

Min, C., Ahmad, R., Kamaruddin, S., \& Azid, I. (2011), "Development of autonomous maintenance implementation framework for semiconductor industries", International Journal of Industrial and Systems Engineering, Vol.9 No.3, pp.268-297.

Miranda, S., \& Lopes, I. (2015), "Development of autonomous maintenance in a furniture company", In Proceedings of the World Congress on Engineering (Vol.2).

Montgomery, D. (2013), Design and analysis of experiments, Wiley, New York.

Mosyurchak, A., Veselkov, V., Turygin, A., \& Hammer, M. (2017), "Prognosis of behaviour of machine tool spindles, their diagnostics and maintenance", MM Science Journal, pp.2100-2104.

Mourtzis, D., Angelopoulos, J., \& Zogopoulos, V. (2021), "Integrated and adaptive AR maintenance and shopfloor rescheduling", Computers in Industry, Vol.125, pp.103383. 
Mourtzis, D., Angelopoulos, J., \& Panopoulos, N. (2020), "Intelligent Predictive Maintenance and Remote Monitoring Framework for Industrial Equipment based on Mixed Reality", Frontiers in Mechanical Engineering, Vol.6, pp.99.

Mourtzis, D., Siatras, V., \& Angelopoulos, J. (2020), "Real-time remote maintenance support based on Augmented Reality (AR)", Applied Sciences, Vol.10 No.5, pp.1855.

Mourtzis, D., \& Vlachou, E. (2018), "A cloud-based cyber-physical system for adaptive shop-floor scheduling and condition-based maintenance", Journal of Manufacturing Systems, Vol.47, pp.179-198.

Mourtzis, D., Vlachou, E., \& Milas, N. (2016), "Industrial big data as a result of IoT adoption in manufacturing", Procedia CIRP, Vol.55, pp.290-295.

Murray, C.E. (2009), "Diffusion of innovation theory: A bridge for the research-practice gap in counselling", Journal of Counseling \& Development, Vol.87 No.1, pp.108-116.

Mustonen-Ollila, E., Lyytinen, K. (2003), "Why organizations adopt information system process innovations: a longitudinal study using Diffusion of Innovation theory", Information Systems Journal, Vol.13 No.3, pp.275-297.

Musman, A., \& Ahmad, R. (2018), "Critical component identification and autonomous maintenance activities determination using fuzzy analytical hierarchy process method", International Journal of Industrial and Systems Engineering, Vol.28 No.3, pp.360-378.

Myers, R.H., \& Myers, R.H. (1990), Classical and modern regression with applications. Duxbury press, Belmont, CA.

Nakajima, S. (1988), Introduction to TPM: total productive maintenance (Translation), New York, Productivity Press, Inc.

Nallusamy, S., \& Majumdar, G. (2017), "Enhancement of Overall Equipment Effectiveness using Total Productive Maintenance in a Manufacturing Industry", International Journal of Performability Engineering, Vol.13 No.2, pp.173-188.

Narayanamurthy, G., \& Tortorella, G. (2021), "Impact of COVID-19 outbreak on employee performanceModerating role of industry 4.0 base technologies", International Journal of Production Economics, Vol.234, pp.108075. 
Netland, T., \& Ferdows, K. (2014), "What to expect from a corporate lean program", MIT Sloan Management Review, Vol.55 No.3, pp.83-89.

Nowakowski, T., Tubis, A., \& Werbińska-Wojciechowska, S. (2018), "Evolution of technical systems maintenance approaches-review and a case study", In International Conference on Intelligent Systems in Production Engineering and Maintenance (pp.161-174). Springer, Cham.

OECD (2011), ISIC REV. 3 Technology Intensity Definition.

Oldenburg, B.F., Sallis, J.F., Ffrench, M.L., Owen, N. (1999), "Health promotion research and the diffusion and institutionalization of interventions", Health education research, Vol.14 No.1, pp.121-130.

Palmarini, R., Erkoyuncu, J., Roy, R., \& Torabmostaedi, H. (2018), "A systematic review of augmented reality applications in maintenance", Robotics and Computer-Integrated Manufacturing, Vol.49, pp.215-228.

Pascal, V., Toufik, A., Manuel, A., Florent, D., \& Frédéric, K. (2019), “Improvement indicators for Total Productive Maintenance policy”, Control Engineering Practice, Vol.82, pp.86-96.

Podsakoff, P., \& Organ, D. (1986), "Self-reports in organizational research: problems and prospects", Journal of Management, Vol.12 No.4, pp.531-544.

Podsakoff, P., MacKenzie, S., Lee, J., \& Podsakoff, N. (2003), "Common method biases in behavioral research: a critical review of the literature and recommended remedies", Journal of Applied Psychology, Vol.88 No.5, pp.879.

Re, G.M., \& Bordegoni, M. (2014), "An augmented reality framework for supporting and monitoring operators during maintenance tasks", In International conference on virtual, augmented and mixed reality (pp.443-454). Springer, Cham.

Reinhardt, I., Oliveira, J., \& Ring, D. (2020), "Current perspectives on the development of Industry 4.0 in the pharmaceutical sector", Journal of Industrial Information Integration, Vol.18, pp.100131.

Rødseth, H., Schjølberg, P., \& Marhaug, A. (2017), "Deep digital maintenance", Advances in Manufacturing, Vol.5 No.4, pp.299-310.

Rogers, E. (2003), Diffusion of Innovations, 5th Edition, Simon and Schuster, New York. 
Rossini, M., Costa, F., Tortorella, G., \& Staudacher, A. (2019), "The interrelation between Industry 4.0 and lean production: an empirical study on European manufacturers", The International Journal of Advanced Manufacturing Technology, Vol.102 No.9, pp.3963-3976.

Ryan, B., Gross, N. (1943), "The Diffusion of Hybrid Seed Corn in Two Iowa Communities", Rural Sociology, Vol.8 No.1, pp.15.

Sahin, I. (2006), "Detailed review of Rogers' diffusion of innovations theory and educational technology-related studies based on Rogers' theory", Turkish Online Journal of Educational Technology-TOJET, Vol.5 No.2, pp.1423.

Sahoo, S. (2019), "Assessment of TPM and TQM practices on business performance: a multi-sector analysis", Journal of Quality in Maintenance Engineering, Vol.25 No.3, pp.412-434.

Salkin, C., Oner, M., Ustundag, A., \& Cevikcan, E. (2018), "A conceptual framework for Industry 4.0", In Industry 4.0: Managing the Digital Transformation (pp. 3-23). Springer, Cham.

Santos, I., Machado, M., Russo, E., Manguinho, D., Almeida, V., Wo, R., ... \& Silva, E. (2015), "Big data analytics for predictive maintenance modeling: Challenges and opportunities", In OTC Brasil. Offshore Technology Conference.

Shah, R., \& Ward, P. (2003), "Lean manufacturing: context, practice bundles, and performance", Journal of Operations Management, Vol.21 No.2, pp.129-149.

Shah, R., \& Ward, P. (2007), "Defining and developing measures of lean production", Journal of Operations Management, Vol.25 No.4, pp.785-805.

Silvestri, L., Forcina, A., Introna, V., Santolamazza, A., \& Cesarotti, V. (2020), "Maintenance transformation through Industry 4.0 technologies: A systematic literature review", Computers in Industry, Vol.123, pp.103335.

Smith, T. (1983), "On the validity of inferences from non-random samples", Journal of the Royal Statistical Society: Series A (General), Vol.146 No.4, pp.394-403.

Stone, K. (2012), "Four decades of lean: a systematic literature review", International Journal of Lean Six Sigma, Vol.3 No.2, pp.112-132.

Sun, M., Wu, F., Ng, C., \& Cheng, T. (2021), "Effects of imperfect IoT-enabled diagnostics on maintenance services: A system design perspective", Computers \& Industrial Engineering, Vol.153, pp.107096. 
Susto, G., Schirru, A., Pampuri, S., McLoone, S., \& Beghi, A. (2014), "Machine learning for predictive maintenance: A multiple classifier approach", IEEE Transactions on Industrial Informatics, Vol.11 No.3, pp.812820.

Takeda, N., Kita, E., Nakagawa, E., \& Suzuki, H. (2016), "Using Operation Information in Reliability Design and Maintenance: Analytics for the IoT Era", Hitachi Review, Vol.65 No.9, pp.451.

Tortorella, G., Cauchick-Miguel, P., Li, W., Staines, J., \& McFarlane, D. (2021c), "What does operational excellence mean in the Fourth Industrial Revolution era?", International Journal of Production Research, (forthcoming).

Tortorella, G., \& Fettermann, D. (2018), "Implementation of Industry 4.0 and lean production in Brazilian manufacturing companies", International Journal of Production Research, Vol.56 No.8, pp.2975-2987.

Tortorella, G., Fettermann, D., Frank, A. \& Marodin, G. (2018), "Lean manufacturing implementation: Leadership styles and contextual variables", International Journal of Operations \& Production Management, Vol.38 No.5, pp.1205-1227.

Tortorella, G., Fogliatto, F., Cauchick-Miguel, P., Kurnia, S., \& Jurburg, D. (2021b), "Integration of Industry 4.0 technologies into Total Productive Maintenance practices", International Journal of Production Economics, Vol.240, pp.108224.

Tortorella, G., Fogliatto, F., Espôsto, K., Vergara, A., Vassolo, R., Tlapa, D., \& Narayanamurthy, G. (2020b), "Measuring the effect of Healthcare 4.0 implementation on hospitals' performance", Production Planning \& Control, (forthcoming).

Tortorella, G., Giglio, R., \& van Dun, D. (2019), "Industry 4.0 adoption as a moderator of the impact of lean production practices on operational performance improvement", International Journal of Operations \& Production Management, Vol.39 No.6/7/8, pp.860-886.

Tortorella, G., Miorando, R., Caiado, R., Nascimento, D., \& Staudacher, A. (2021a), "The mediating effect of employees' involvement on the relationship between Industry 4.0 and operational performance improvement", Total Quality Management \& Business Excellence, Vol.32 No.1-2, pp.119-133.

Tortorella, G., Vergara, A., Garza-Reyes, J., \& Sawhney, R. (2020a), "Organizational learning paths based upon industry 4.0 adoption: An empirical study with Brazilian manufacturers", International Journal of Production Economics, Vol.219, pp.284-294. 
Toews, D. (2003), "The New Tarde: Sociology after the End of the Social", Theory Culture \& Society, Vol.20 No.5, pp.81-98.

Urbinati, A., Bogers, M., Chiesa, V., \& Frattini, F. (2019), "Creating and capturing value from Big Data: A multiple-case study analysis of provider companies", Technovation, Vol.84, pp.21-36.

Wan, J., Tang, S., Li, D., Wang, S., Liu, C., Abbas, H., \& Vasilakos, A. (2017), "A manufacturing big data solution for active preventive maintenance", IEEE Transactions on Industrial Informatics, Vol.13 No.4, pp.2039-2047.

Weckenborg, C., Kieckhäfer, K., Müller, C., Grunewald, M., \& Spengler, T. (2019), "Balancing of assembly lines with collaborative robots", Business Research, (forthcoming).

Wickramasinghe, G. \& Perera, A. (2016), "Effect of total productive maintenance practices on manufacturing performance: Investigation of textile and apparel manufacturing firms", Journal of Manufacturing Technology Management, Vol.27 No.5, pp.713-729.

Wits, W., García, J., \& Becker, J. (2016), "How additive manufacturing enables more sustainable end-user maintenance, repair and overhaul (MRO) strategies", Procedia CIRP, Vol.40, pp.693-698.

Yan, J., Meng, Y., Lu, L., \& Li, L. (2017), "Industrial big data in an industry 4.0 environment: Challenges, schemes, and applications for predictive maintenance", IEEE Access, Vol.5, pp.23484-23491.

Zenisek, J., Holzinger, F., \& Affenzeller, M. (2019), "Machine learning based concept drift detection for predictive maintenance", Computers \& Industrial Engineering, Vol.137, pp.106031.

Zheng, T., Ardolino, M., Bacchetti, A., \& Perona, M. (2020), "The applications of Industry 4.0 technologies in manufacturing context: a systematic literature review", International Journal of Production Research, (forthcoming).

Zonta, T., Costa, C., Rosa Righi, R., Lima, M., Trindade, E., \& Li, G. (2020), "Predictive maintenance in the Industry 4.0: A systematic literature review", Computers \& Industrial Engineering, pp.106889. 


\section{List of abbreviations:}

$\mathrm{AM}=$ Autonomous maintenance

$\mathrm{CBM}=$ Condition-based maintenance

DIT $=$ Diffusion of innovation theory

EFA $=$ Exploratory factor analysis

$\mathrm{EHSM}=$ Environment, health, and safety maintenance

I4.0 $=$ Industry 4.0

IoT $=$ Internet-of-Things

MTBF $=$ Mean-time-between-failures

MTTF $=$ Mean-time-to-failure

MTTR $=$ Mean-time-to-repair

OECD $=$ Organization for Economic Cooperation and Development

OEE $=$ Overall equipment effectiveness

OLS $=$ Ordinary least squares

$\mathrm{PC}=$ Principal component

$\mathrm{PFM}=$ Planned and focused maintenance

PROC_ACT $=$ Processing and actuation

$\mathrm{QDM}=$ Quality and development maintenance

SENS_COMM $=$ Sensing and communication

$\mathrm{TPM}=$ Total productive maintenance

$\mathrm{VIF}=$ Variance inflation factors 
Table 1 - Consolidation of main TPM practices

\begin{tabular}{|c|c|c|c|c|c|c|c|c|c|c|c|}
\hline 4 & $\begin{array}{l}\text { McKone } \\
\text { et al. } \\
(2001)\end{array}$ & $\begin{array}{l}\text { Cua et } \\
\text { al. } \\
(2001)\end{array}$ & $\begin{array}{c}\text { Shah } \\
\text { and } \\
\text { Ward } \\
(2003)\end{array}$ & $\begin{array}{c}\text { Shah } \\
\text { and } \\
\text { Ward } \\
(2007)\end{array}$ & $\begin{array}{c}\text { Ahuja } \\
\text { and } \\
\text { Khamba } \\
\text { (2008b) } \\
\end{array}$ & $\begin{array}{c}\text { Konecny } \\
\text { and } \\
\text { Thun } \\
(2011) \\
\end{array}$ & $\begin{array}{l}\text { Jain et } \\
\text { al. } \\
(2014)\end{array}$ & $\begin{array}{l}\text { Wickramasinghe } \\
\text { and Perera } \\
\text { (2016) }\end{array}$ & $\begin{array}{l}\text { Sahoo } \\
(2019)\end{array}$ & $\begin{array}{l}\text { Ighravwe } \\
\text { and Oke } \\
(2020)\end{array}$ & $\begin{array}{l}\text { Citation } \\
\text { frequency } \\
(\%)\end{array}$ \\
\hline$m_{1}$-Fostering operator ownership & $\sqrt{ }$ & $\sqrt{ }$ & & $\sqrt{ }$ & $\sqrt{ }$ & & $\sqrt{ }$ & $\sqrt{ }$ & $\sqrt{ }$ & & $70 \%$ \\
\hline$m_{2}$-Perform cleaning, lubricating, tightening, adjustment, inspection, readjustment on production equipment & $\sqrt{ }$ & $\sqrt{ }$ & & & $\sqrt{ }$ & $\sqrt{ }$ & $\sqrt{ }$ & $\sqrt{ }$ & $\sqrt{ }$ & & $70 \%$ \\
\hline$m_{3}$-Operators understand the cause and effect of equipment deterioration & & $\sqrt{ }$ & & & & $\sqrt{ }$ & & & $\sqrt{ }$ & & $30 \%$ \\
\hline$m_{4}$-Standardization of AM checks & & & & & & & & $\sqrt{ }$ & $\sqrt{ }$ & $\sqrt{ }$ & $30 \%$ \\
\hline$m_{5}$-Systematic identification and elimination of losses & & & & & $\sqrt{ }$ & $\sqrt{ }$ & $\sqrt{ }$ & $\sqrt{ }$ & & $\sqrt{ }$ & $50 \%$ \\
\hline$m_{6}$-Working out loss structure and loss mitigation through structured why-why, FMEA analysis & & & & & $\sqrt{ }$ & & $\sqrt{ }$ & $\sqrt{ }$ & & $\sqrt{ }$ & $40 \%$ \\
\hline$m_{7}$-Groups are formed to solve specific problems & & & & & & $\sqrt{ }$ & & & $\sqrt{ }$ & & $20 \%$ \\
\hline$m_{8}$-Achieve improved system efficiency (e.g., schedule compliance) & & & & & $\sqrt{ }$ & $\sqrt{ }$ & $\sqrt{ }$ & & & $\sqrt{ }$ & $40 \%$ \\
\hline$m_{9}$-Improved OEE on production systems & & & & & $\sqrt{ }$ & & $\sqrt{ }$ & & & $\sqrt{ }$ & $30 \%$ \\
\hline$m_{10}$-Planning efficient and effective PM, PdM, and TBM systems over the equipment life cycle & & & $\sqrt{ }$ & $\sqrt{ }$ & $\sqrt{ }$ & & $\sqrt{ }$ & & $\sqrt{ }$ & & $50 \%$ \\
\hline$m_{11}$-There is a specific shift (or part of a shift) reserved for maintenance activities & & $\sqrt{ }$ & $\sqrt{ }$ & $\sqrt{ }$ & & & & & & $\sqrt{ }$ & $40 \%$ \\
\hline$m_{12}$-Establishing PM check sheets & $\sqrt{ }$ & & $\sqrt{ }$ & & $\sqrt{ }$ & & $\sqrt{ }$ & $\sqrt{ }$ & & & $50 \%$ \\
\hline$m_{13}$-Improving mean time between failures and mean time to repair & & & & & $\sqrt{ }$ & & $\sqrt{ }$ & $\sqrt{ }$ & & $\sqrt{ }$ & $40 \%$ \\
\hline$m_{14}$-Achieving zero defects & & & & & $\sqrt{ }$ & & $\sqrt{ }$ & $\sqrt{ }$ & & $\sqrt{ }$ & $40 \%$ \\
\hline$m_{15}$-Tracking and addressing equipment problems and root causes & $\sqrt{ }$ & & & $\sqrt{ }$ & $\sqrt{ }$ & & $\sqrt{ }$ & $\sqrt{ }$ & & & $50 \%$ \\
\hline$m_{16}$-Setting 3M (machine/man/material) conditions & & & & & $\sqrt{ }$ & & $\sqrt{ }$ & $\sqrt{ }$ & & $\sqrt{ }$ & $40 \%$ \\
\hline$m_{17}$-Imparting technological, quality control, interpersonal skills multi-skilling of employees & $\sqrt{ }$ & & & & $\sqrt{ }$ & $\sqrt{ }$ & $\sqrt{ }$ & $\sqrt{ }$ & & & $60 \%$ \\
\hline$m_{18}$-Constant seek for next generation of technology & & & & & & $\sqrt{ }$ & & & $\sqrt{ }$ & $\sqrt{ }$ & $40 \%$ \\
\hline$m_{19}$-Aligning employees to organizational goals & & & & & $\sqrt{ }$ & & $\sqrt{ }$ & $\sqrt{ }$ & & & $40 \%$ \\
\hline$m_{20}$-Periodic skill evaluation and updating & $\sqrt{ }$ & & & & $\sqrt{ }$ & $\sqrt{ }$ & $\sqrt{ }$ & $\sqrt{ }$ & & & $60 \%$ \\
\hline$m_{21}$-Ensuring safe working environment & & & & & $\sqrt{ }$ & & $\sqrt{ }$ & $\sqrt{ }$ & & & $40 \%$ \\
\hline$m_{22}$-Providing appropriate work environment & $\sqrt{ }$ & & & & $\sqrt{ }$ & & $\sqrt{ }$ & $\sqrt{ }$ & & $\sqrt{ }$ & $60 \%$ \\
\hline$m_{23}$-Eliminating incidents of injuries and accidents & & & & & $\sqrt{ }$ & & $\sqrt{ }$ & $\sqrt{ }$ & $\sqrt{ }$ & $\sqrt{ }$ & $50 \%$ \\
\hline$m_{24}$-Providing standard operating procedures & & & $\sqrt{ }$ & & $\sqrt{ }$ & & $\sqrt{ }$ & & & $\sqrt{ }$ & $40 \%$ \\
\hline$m_{25}$-Improving synergy between various business functions & & & & & $\sqrt{ }$ & & $\sqrt{ }$ & $\sqrt{ }$ & & & $30 \%$ \\
\hline$m_{26}$-Removing procedural hassles & & & & & $\sqrt{ }$ & & $\sqrt{ }$ & $\sqrt{ }$ & & & $30 \%$ \\
\hline$m_{27}$-Focusing on addressing cost-related issues & & & & & $\sqrt{ }$ & & $\sqrt{ }$ & $\sqrt{ }$ & & & $30 \%$ \\
\hline$m_{28}$-Applying $5 \mathrm{~S}$ in office and working areas & & & & & $\sqrt{ }$ & & $\sqrt{ }$ & $\sqrt{ }$ & $\sqrt{ }$ & & $40 \%$ \\
\hline$m_{29}$-Minimal problems and running in time on new equipment & & & $\sqrt{ }$ & & $\sqrt{ }$ & & $\sqrt{ }$ & $\sqrt{ }$ & & $\sqrt{ }$ & $50 \%$ \\
\hline$m_{30}$-Utilizing learning from existing systems to new systems & & & $\sqrt{ }$ & & $\sqrt{ }$ & & $\sqrt{ }$ & $\sqrt{ }$ & & & $40 \%$ \\
\hline$m_{31}$-Maintenance improvement initiatives & $\sqrt{ }$ & & $\sqrt{ }$ & & $\sqrt{ }$ & & $\sqrt{ }$ & $\sqrt{ }$ & & $\sqrt{ }$ & $60 \%$ \\
\hline
\end{tabular}

Notes: AM = Autonomous Maintenance; FMEA = Failure Mode and Effect Analysis; PdM = Predictive Maintenance; PM = Preventive Maintenance; TBM = Time-Based Maintenance- 
Table 2 - I4.0 technologies reported in the literature

\begin{tabular}{|c|c|c|c|c|c|c|c|c|c|c|c|}
\hline Technology & $\begin{array}{c}\text { Chiarello } \\
\text { et al. } \\
(2018) \\
\end{array}$ & $\begin{array}{c}\text { Fatorachian } \\
\text { and Kazemi } \\
(2018)\end{array}$ & $\begin{array}{c}\text { Dalenogare } \\
\text { et al. } \\
(2018) \\
\end{array}$ & $\begin{array}{l}\text { Frank } \\
\text { et al. } \\
(2019) \\
\end{array}$ & $\begin{array}{l}\text { Rossini } \\
\text { et al. } \\
(2019) \\
\end{array}$ & $\begin{array}{l}\text { Zheng } \\
\text { et al. } \\
(2020)\end{array}$ & $\begin{array}{l}\text { Chiarini } \\
\text { et al. } \\
(2020) \\
\end{array}$ & $\begin{array}{c}\text { Tortorella } \\
\text { et al. } \\
(2020 \mathrm{a}) \\
\end{array}$ & $\begin{array}{l}\text { Tortorella } \\
\text { et al. } \\
\text { (2021a) }\end{array}$ & $\begin{array}{c}\text { Narayanamurthy, } \\
\text { and Tortorella } \\
(2021)\end{array}$ & $\begin{array}{c}\text { Citation } \\
\text { frequency } \\
(\%)\end{array}$ \\
\hline$t_{1}$-Wireless sensors & $\sqrt{ }$ & $\sqrt{ }$ & $\sqrt{ }$ & $\sqrt{ }$ & $\sqrt{ }$ & & & & $\sqrt{ }$ & & $60 \%$ \\
\hline$t_{2}$-Internet-of-Things & $\sqrt{ }$ & $\sqrt{ }$ & $\sqrt{ }$ & $\sqrt{ }$ & $\sqrt{ }$ & $\sqrt{ }$ & $\sqrt{ }$ & $\sqrt{ }$ & $\sqrt{ }$ & $\sqrt{ }$ & $100 \%$ \\
\hline$t_{3}$-Big data & $\sqrt{ }$ & $\sqrt{ }$ & $\sqrt{ }$ & $\sqrt{ }$ & $\sqrt{ }$ & $\sqrt{ }$ & $\sqrt{ }$ & $\sqrt{ }$ & $\sqrt{ }$ & $\sqrt{ }$ & $100 \%$ \\
\hline$t_{4}$-Cloud computing & & $\sqrt{ }$ & $\sqrt{ }$ & $\sqrt{ }$ & $\sqrt{ }$ & $\sqrt{ }$ & $\sqrt{ }$ & $\sqrt{ }$ & $\sqrt{ }$ & $\sqrt{ }$ & $90 \%$ \\
\hline$t_{5}$-Remote control/monitoring & & $\sqrt{ }$ & $\sqrt{ }$ & $\sqrt{ }$ & $\sqrt{ }$ & & & & $\sqrt{ }$ & & $50 \%$ \\
\hline$t_{6}-3 \mathrm{D}$ printing & $\sqrt{ }$ & & $\sqrt{ }$ & $\sqrt{ }$ & $\sqrt{ }$ & $\sqrt{ }$ & $\sqrt{ }$ & & $\sqrt{ }$ & & $70 \%$ \\
\hline$t_{7}$-Collaborative robots & & & & $\sqrt{ }$ & $\sqrt{ }$ & $\sqrt{ }$ & $\sqrt{ }$ & & & & $40 \%$ \\
\hline$t_{8}$-Machine/Deep learning & & $\sqrt{ }$ & $\sqrt{ }$ & $\sqrt{ }$ & $\sqrt{ }$ & & & $\sqrt{ }$ & & $\sqrt{ }$ & $60 \%$ \\
\hline$t_{9}$-Augmented reality/simulation & $\sqrt{ }$ & & & $\sqrt{ }$ & $\sqrt{ }$ & $\sqrt{ }$ & & & $\sqrt{ }$ & & $50 \%$ \\
\hline
\end{tabular}

Table 3 -EFA to validate the maintenance performance construct

\begin{tabular}{|c|c|c|c|c|}
\hline Performance indicators & Mean & Standard deviation & Communalities & 1 \\
\hline Mean time to repair (MTTR) & 3.237 & 1.097 & 0.645 & 0.803 \\
\hline Mean time between failures (MTBF) & 3.212 & 1.079 & 0.643 & 0.801 \\
\hline Mean time to failure (MTTF) & 3.246 & 1.058 & 0.631 & 0.794 \\
\hline Overall Equipment Effectiveness (OEE) & 3.363 & 1.040 & 0.552 & 0.743 \\
\hline Cost & 3.284 & 1.130 & 0.357 & 0.597 \\
\hline Safety (injuries and work accidents) & 3.651 & 1.068 & 0.320 & 0.566 \\
\hline \multirow{4}{*}{\multicolumn{2}{|c|}{$\begin{array}{l}\text { Extraction sums of squared loadings } \\
\% \text { of variance } \\
\text { Cronbach's alpha }(n=318) \\
\text { Kaiser-Meyer-Olkin measure of sampling adequacy } \\
\text { Bartlett's test of sphericity }\left(\chi^{2} / \mathrm{df}\right)\end{array}$}} & & & $\begin{array}{c}3.148 \\
52.471\end{array}$ \\
\hline & & & & $\begin{array}{c}52.471 \\
0.823\end{array}$ \\
\hline & & & & 0.846 \\
\hline & & & & $603.68 / 15^{* * *}$ \\
\hline
\end{tabular}

Notes: Extraction method: Principal Component Analysis; ${ }^{* * * *} p$-value $<0.01$. Bold numbers indicate which practices were assigned to which constructs. 
Table 4 - EFA to validate the TPM constructs

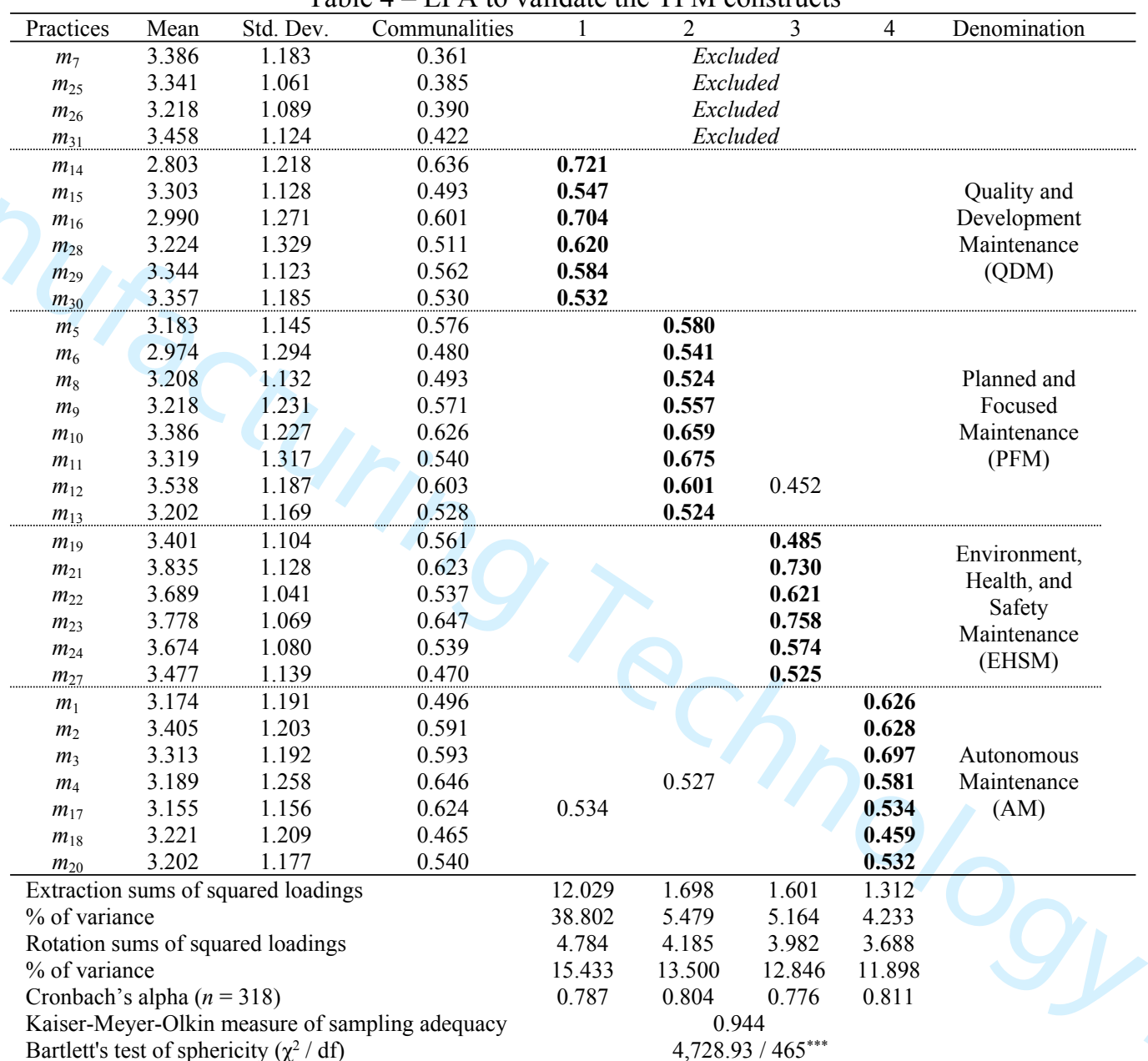

Notes: Extraction method: Principal Component Analysis; Rotation Method: Varimax with Kaiser normalization; ${ }^{* * *} p$-value $<0.01$. Bold numbers indicate the assignment of practices to constructs. Factor loadings below 0.45 were suppressed. 
Table 5 - EFA to validate the 14.0 constructs

\begin{tabular}{|c|c|c|c|c|c|c|}
\hline Technologies & Mean & Std. Dev. & Communalities & 1 & 2 & Denomination \\
\hline Wireless sensors & 2.636 & 1.351 & 0.470 & 0.657 & & \multirow{5}{*}{$\begin{array}{l}\text { Sensing and } \\
\text { Communication } \\
\text { (SENS_COMM) }\end{array}$} \\
\hline Internet-of-Things & 2.506 & 1.339 & 0.608 & 0.771 & & \\
\hline Big data & 2.462 & 1.322 & 0.607 & 0.716 & & \\
\hline Cloud computing & 2.848 & 1.390 & 0.568 & 0.750 & & \\
\hline Remote control/monitoring & 3.164 & 1.342 & 0.365 & 0.579 & & \\
\hline $3 \mathrm{D}$ printing & 2.158 & 1.328 & 0.572 & & 0.749 & \multirow{4}{*}{$\begin{array}{l}\text { Processing and } \\
\text { Actuation } \\
\text { (PROC_ACT) }\end{array}$} \\
\hline Collaborative robots & 2.072 & 1.266 & 0.572 & & 0.744 & \\
\hline Machine/Deep learning & 2.158 & 1.350 & 0.646 & & 0.757 & \\
\hline Augmented reality/simulation & 2.025 & 1.306 & 0.607 & & 0.749 & \\
\hline \multicolumn{4}{|c|}{ Extraction sums of squared loadings } & 3.647 & 1.367 & \\
\hline \multirow{2}{*}{\multicolumn{4}{|c|}{$\%$ of variance }} & 40.52 & 15.18 & \\
\hline & & \multicolumn{2}{|c|}{ Rotation sums of squared loadings } & 2.583 & 2.430 & \\
\hline \multicolumn{4}{|c|}{$\begin{array}{l}\text { Rotation sums of squared loadings } \\
\% \text { of variance }\end{array}$} & 28.70 & 27.00 & \\
\hline \multicolumn{4}{|c|}{ Cronbach's alpha $(n=318)$} & 0.790 & 0.802 & \\
\hline \multicolumn{4}{|c|}{ Kaiser-Meyer-Olkin measure of sampling adequacy } & & \\
\hline \multicolumn{4}{|c|}{ Bartlett's test of sphericity $\left(\chi^{2} / \mathrm{df}\right)$} & \multicolumn{2}{|c|}{$783.23 / 36^{* * *}$} & \\
\hline
\end{tabular}

Notes: Extraction method: Principal Component Analysis; Rotation Method: Varimax with Kaiser normalization; ${ }^{* * *} p$-value $<0.01$. Bold numbers indicate the assignment of technologies to constructs. Factor loadings below 0.45 were suppressed.

Table $6-\hat{\beta}$ coefficients for hierarchical regression analyses

\begin{tabular}{lccc}
\hline \multicolumn{1}{c}{ Variables } & Model A & Model B & Model C \\
\hline Socioeconomic context & 0.202 & 0.128 & 0.114 \\
Technology intensity & 0.081 & -0.060 & -0.042 \\
Company size & -0.046 & $-0.168^{*}$ & -0.149 \\
Time of TPM adoption & $0.423^{* * * *}$ & 0.028 & 0.016 \\
SENS_COMM & & 0.071 & 0.052 \\
PROC_ACT & & $0.186^{* * *}$ & $0.215^{* * *}$ \\
AM & & $0.219^{* * *}$ & $0.241^{* * *}$ \\
PFM & $0.183^{* * *}$ & $0.150^{*}$ \\
EHSM & $0.166^{* *}$ & $0.155^{* *}$ \\
QDM & -0.011 & 0.011 \\
AM $x$ SENS_COMM & & & 0.085 \\
PFM $x$ SENS_COMM & & & $-0.132^{*}$ \\
QDM $x$ SENS_COMM & & & -0.030 \\
EHSM $x$ SENS_COMM & & & $0.206^{* * *}$ \\
AM $x$ PROC_ACT & & & -0.014 \\
PFM $x$ PROC_ACT & & & -0.006 \\
QDM $x$ PROC_ACT & & & -0.009 \\
EHSM $x$ PROC_ACT & & -0.083 \\
\hline$F$-value & $4.680^{* * *}$ & $19.042^{* * *}$ & $11.468^{* * *}$ \\
$R^{2}$ & 0.384 & 0.414 \\
Adj. $R^{2}$ & 0.047 & 0.364 & 0.394 \\
Change in $R^{2}$ & & $0.328^{* * *}$ & $0.030^{*}$ \\
\hline \multicolumn{2}{c}{ Notes: ${ }^{*} p$-value $<0.10 ;{ }^{* *} p$-value $<0.05 ;{ }^{* * *} p$-value $<0.01}$.
\end{tabular}




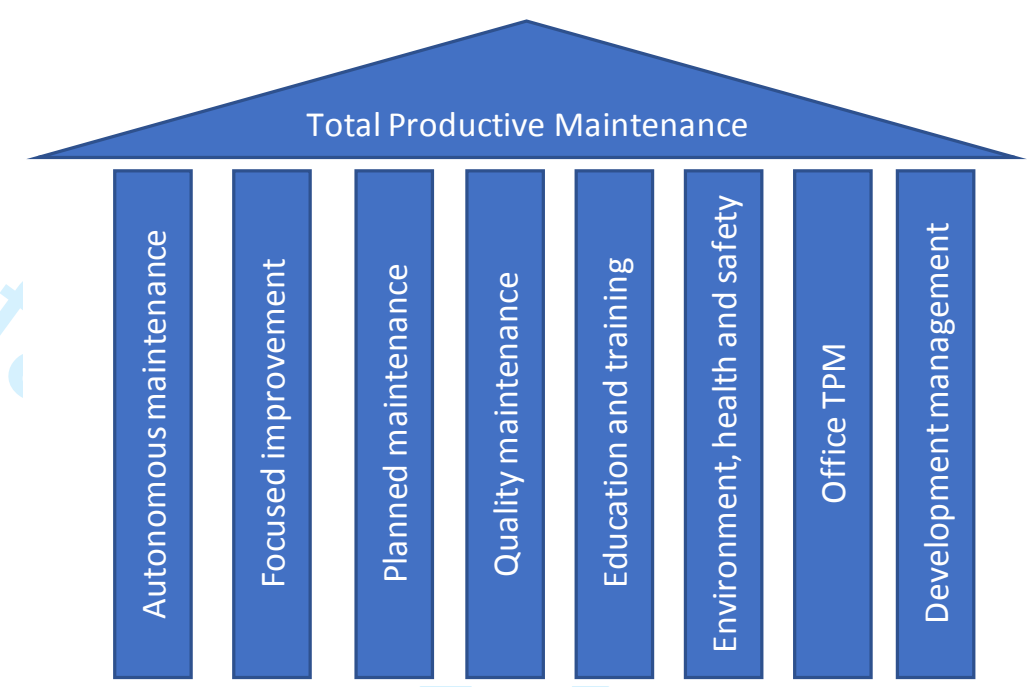

Figure 1 - Illustration of TPM pillars

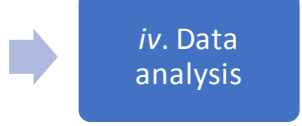

Figure 2 - Steps of the proposed method 

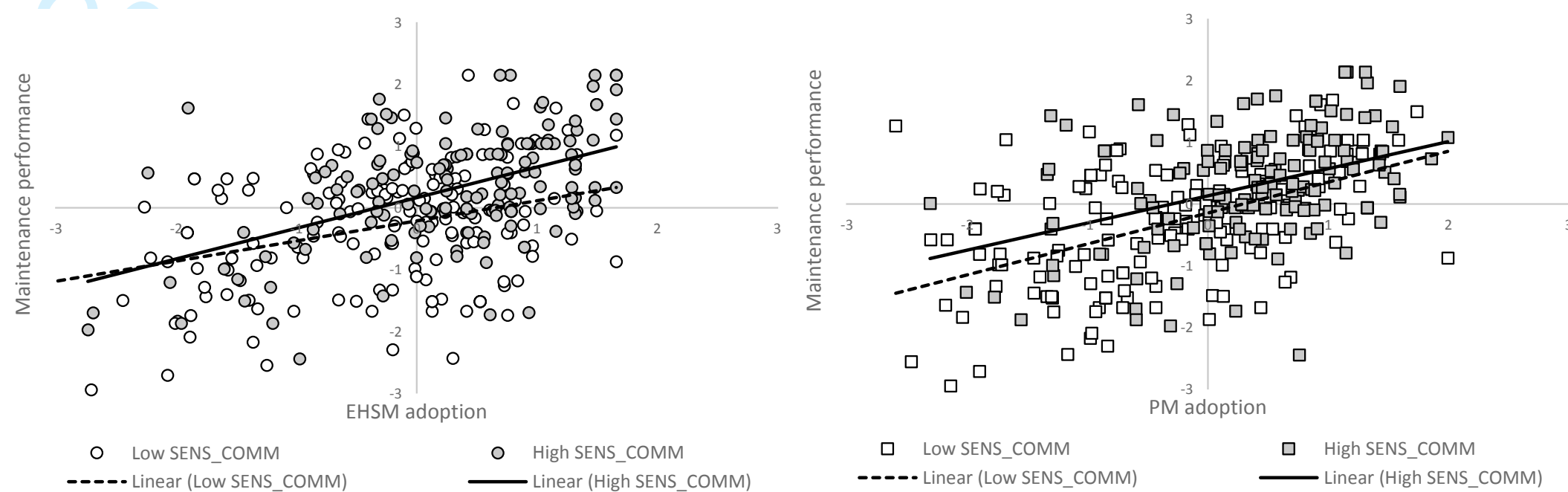

- Low SENS_COMM

- High SENS_COMM

Linear (High SENS_COMM)

--.--. Linear (Low SENS_COMM)

Linear (High SENS_COMM)

Figure 3 - Moderation of SENS_COMM technologies on the effect of EHSM and PM practices on maintenance performance

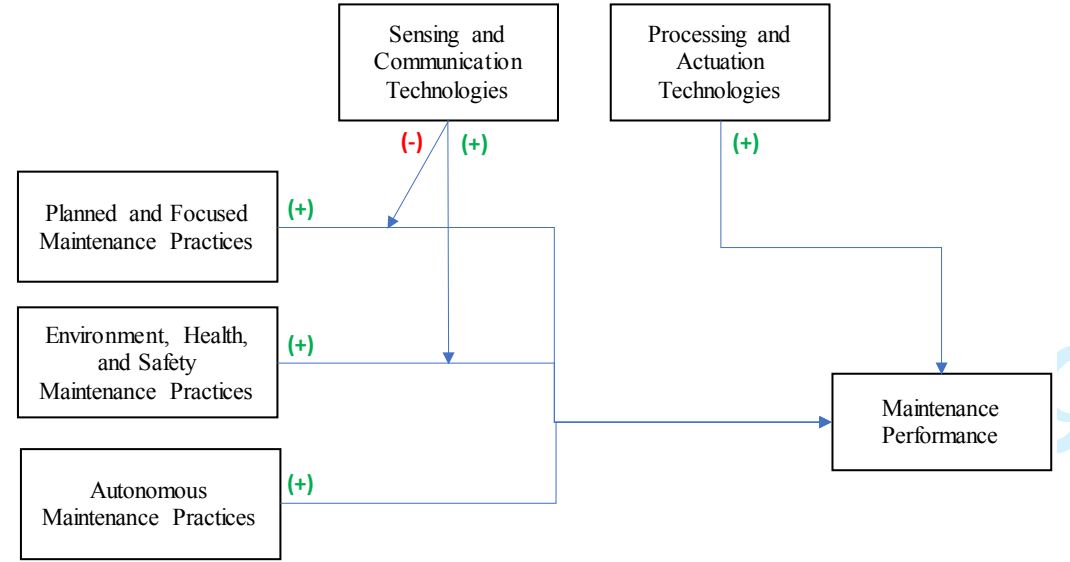

Quality and

Development

Maintenance Practices

Figure 4 - Empirically validated relationships 
Appendix A - Sample characteristics $(n=318)$

\begin{tabular}{|c|c|c|}
\hline \multicolumn{3}{|l|}{ Country } \\
\hline Brazil & 43 & $13.5 \%$ \\
\hline Chile & 12 & $3.8 \%$ \\
\hline Mexico & 32 & $10.1 \%$ \\
\hline Argentina & 6 & $1.9 \%$ \\
\hline Uruguay & 31 & $9.7 \%$ \\
\hline Kuwait & 4 & $1.3 \%$ \\
\hline Spain & 32 & $10.1 \%$ \\
\hline Italy & 22 & $6.9 \%$ \\
\hline Australia & 20 & $6.3 \%$ \\
\hline India & 40 & $12.6 \%$ \\
\hline Morocco & 58 & $18.2 \%$ \\
\hline Oman & 5 & $1.6 \%$ \\
\hline Qatar & 2 & $0.6 \%$ \\
\hline United Arabia Emirates & 6 & $1.9 \%$ \\
\hline Saudi Arabia & 5 & $1.6 \%$ \\
\hline \multicolumn{3}{|c|}{ Industry sector } \\
\hline Automotive & 71 & $22.3 \%$ \\
\hline Metal-mechanics & 66 & $20.8 \%$ \\
\hline Machine and equipment & 42 & $13.2 \%$ \\
\hline Food and beverage & 38 & $11.9 \%$ \\
\hline Chemical & 30 & $9.4 \%$ \\
\hline Pharmaceutical & 22 & $6.9 \%$ \\
\hline Electronics & 18 & $5.7 \%$ \\
\hline Aerospace & 12 & $3.8 \%$ \\
\hline Others & 19 & $6.0 \%$ \\
\hline \multicolumn{3}{|c|}{ Socioeconomic context } \\
\hline Emerging & 244 & $76.7 \%$ \\
\hline Developed & 74 & $23.3 \%$ \\
\hline \multicolumn{3}{|l|}{ Company size } \\
\hline Less than or equal to 500 employ & 152 & $47.8 \%$ \\
\hline More than 500 employees & 166 & $52.2 \%$ \\
\hline \multicolumn{3}{|c|}{ Company's technological intensity ${ }^{\text {a }}$} \\
\hline Low and mid-low & 160 & $50.3 \%$ \\
\hline High and mid-high & 158 & $49.7 \%$ \\
\hline \multicolumn{3}{|c|}{ Time of TPM adoption in the company } \\
\hline Less than or equal to 5 years & 157 & $49.4 \%$ \\
\hline More than 5 years & 161 & $50.6 \%$ \\
\hline \multicolumn{3}{|c|}{ Respondent's work experience } \\
\hline Less than or equal to 5 years & 80 & $25.2 \%$ \\
\hline More than 5 years & 238 & $74.8 \%$ \\
\hline \multicolumn{3}{|c|}{ Respondent's role } \\
\hline Technician / Analyst / Engineer & 101 & $31.8 \%$ \\
\hline Supervisor / Coordinator & 82 & $25.8 \%$ \\
\hline Manager / Director & 135 & $42.4 \%$ \\
\hline
\end{tabular}

Note: ${ }^{a}$ Refer to OECD (2011). 


\section{Appendix B - Applied Questionnaire}

1 - Please, complete below the information about you and your company:

a) Country where you are located:

b) Your work experience: ( ) Less than 5 years ( ) More than 5 years

c) Your role in the company: ( ) Technician/Analyst/Engineer

\section{( ) Supervisor/Coordinator \\ ( ) Manager/Director}

d) Your company sector:

e) $\mathrm{N}^{\circ}$ of employees in your company: ( ) Less than 500 employees

( ) More than 500 employees

f) Adoption of Total Productive Maintenance (TPM) in your company: ( ) Less than 5 years

\section{( ) More than 5 years}

2 - Please, indicate the adoption level of the following maintenance practices in your company:

Scale: from 1 (no adoption) to 5 (full adoption)

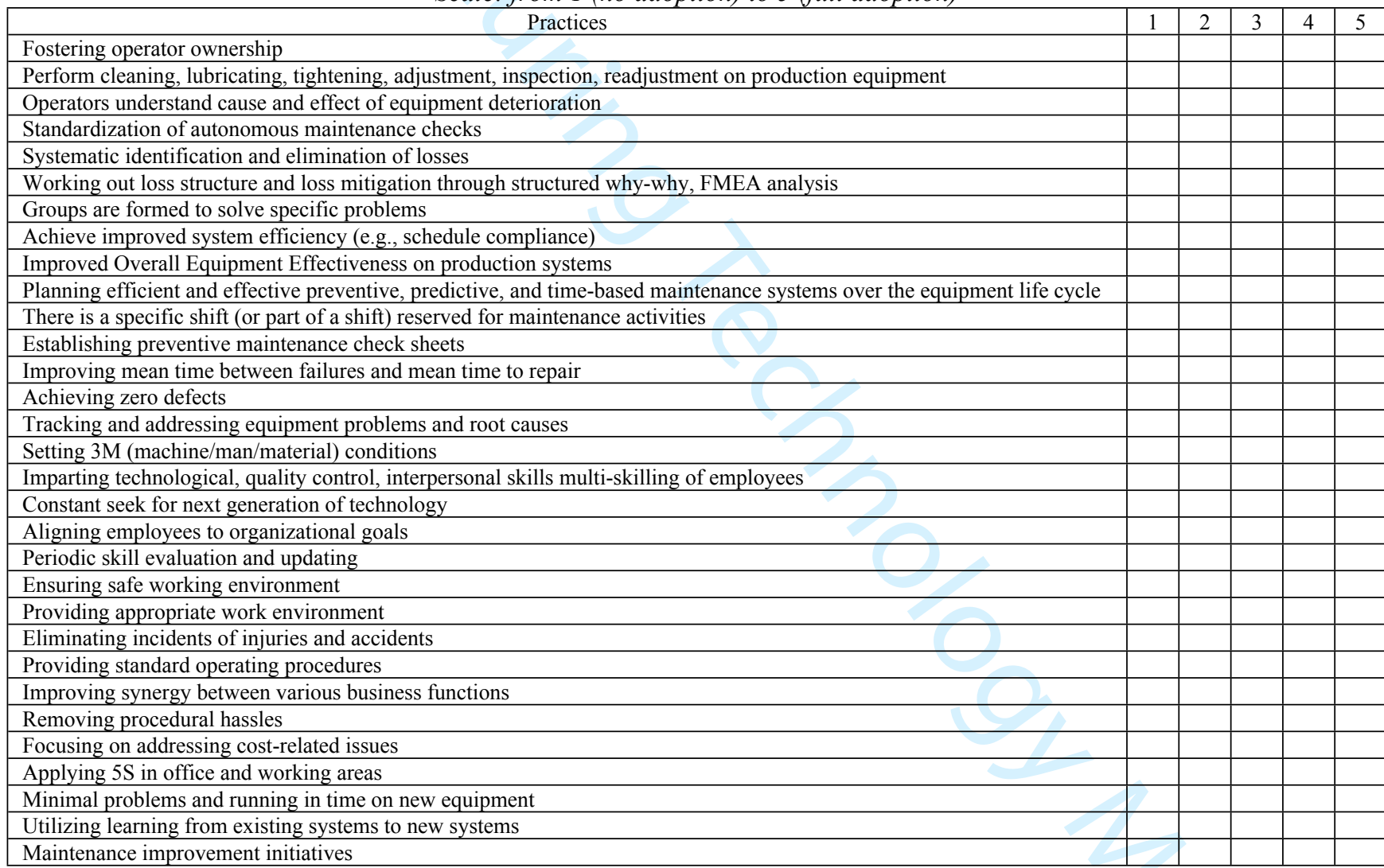

3 - Please, indicate the adoption level of the following digital technologies in your company:

Scale: from 1 (no adoption) to 5 (full adoption)
\begin{tabular}{|l|c|c|c|c|c|}
\hline \multicolumn{1}{|c|}{ Digital technology } & 1 & 2 & 3 & 4 & 5 \\
\hline Wireless sensors & & & & & \\
\hline Internet-of-Things & & & & & \\
\hline Big data & & & & & \\
\hline Cloud computing & & & & & \\
\hline Remote control/monitoring & & & & & \\
\hline 3D printing & & & & & \\
\hline Collaborative robots & & & & & \\
\hline
\end{tabular}


4 - Please, indicate the improvement level of the following performance indicators in the last two years in your company:

\begin{tabular}{|l|l|l|l|l|l|}
\hline Machine/Deep learning & & & & & \\
\hline Augmented reality/simulation & & & & & \\
\hline
\end{tabular}

Scale: from 1 (significantly worsened) to 5 (significantly improved)
\begin{tabular}{|l|c|c|c|c|c|}
\hline \multicolumn{1}{|c|}{ Performance indicator } & 1 & 2 & 3 & 4 & 5 \\
\hline Mean time to repair (MTTR) & & & & & \\
\hline Mean time between failures (MTBF) & & & & & \\
\hline Mean time to failure (MTTF) & & & & & \\
\hline Overall Equipment Effectiveness (OEE) & & & & & \\
\hline Cost & & & & & \\
\hline Safety (injuries and work accidents) & & & & & \\
\hline
\end{tabular}

